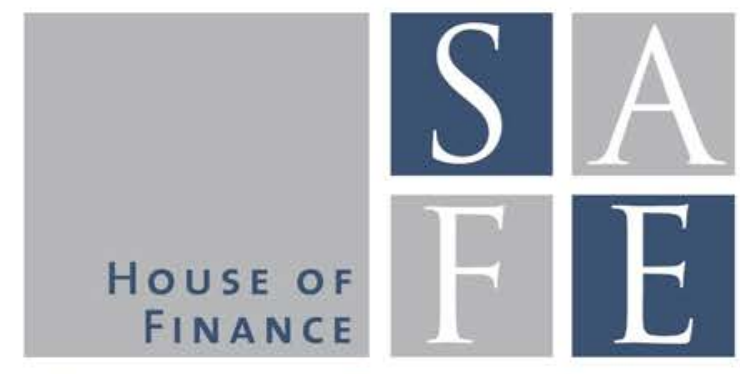

WORKING PAPER SERIES

Anne-Caroline Hüser

\title{
Too Interconnected to Fail: A Survey of the Interbank Networks Literature
}

SAFE Working Paper No. 91

SAFE I Sustainable Architecture for Finance in Europe A cooperation of the Center for Financial Studies and Goethe University Frankfurt 


\section{Non-Technical Summary}

A network approach to banking is particularly important for assessing financial stability and systemic risk. This approach can be instrumental in capturing the externalities that the risk associated with a single institution may create for the entire system. Indeed, from a financial stability perspective, banks should neither be too-big-to-fail nor too-interconnected-to-fail. A better understanding of network externalities may facilitate the adoption of a macroprudential framework for financial supervision. Network externalities arise when risk-taking behavior of individual institutions affects other institutions and the system as a whole. To guide policy it becomes necessary, in this context, to measure the systemic importance of individual banks, i.e. their capacity to generate contagion in the rest of the system. The analysis of interbank networks can provide this guidance.

Against this background we review the literature on interbank networks, which is part of a growing literature on financial networks. The broader financial networks literature is analyzing connections between financial institutions: banks, but also hedge funds, insurance companies, etc. We restrict the survey's focus on the interbank network literature. This survey presents a systematic overview of our current understanding of the structure of interbank networks, of how network characteristics affect contagion in the banking system and of how banks form connections when faced with the possibility of contagion and systemic risk. In particular, we highlight how the theoretical literature on interbank networks offers a coherent way of studying interconnections, contagion processes and systemic risk, while emphasizing at the same time the many challenges that must be addressed before general results on the link between the structure of the interbank network and financial stability can be established.

The theoretical literature has generated a number of insights on the effect of the network structure on contagion. A first result is that the number and magnitude of defaults depend on the network topology. There is now substantial research characterizing those structures that tend to propagate default or alternatively that tend to dampen it. An avenue for further research is to have more realistic network structures on which to analyze contagion. Since empirical studies now provide an increasing number of stylized facts on the interbank network topology, research needs to move beyond deriving results on random networks or on overly simplified structures. Furthermore, the fragility of the system depends on the location in the network of the institution that was initially affected. Intuitively, the failure of core banks is more damaging than the failure of a periphery bank. Finally, another main finding is that there is a trade-off between risk sharing via linkages to other banks and contagion risk due to too many linkages. While the existence of the trade-off is not disputed, there is no consensus on whether a complete network dampens or fuels contagion. Some studies argue that intermediate levels of connectivity are better, for example because the effect of connectivity on contagion is non-monotonic. Recent research argues that a complete network is more resilient to small shocks whereas in the presence of large shocks, less connections are better able to prevent contagion. The lack of consensus hinges on the fact that these studies have been conducted on widely different network structures and under different assumptions about the 
size and type of shocks. Again, conducting analyses on more realistic network structures is required to make a convincing case.

Another shortcoming is that most interbank network models in the literature are static and exogenously given. One limitation of these static models is that they do not provide a dynamic account of link formation. Research is moving in this direction, but most of the dynamic models still use probabilistic link formation by relying on network growth models or on preferential attachment rules. A few recent models rely on endogenous network formation, in which banks purposefully choose the amount of interbank lending and borrowing and thereby create the structure of the interbank network. More work is needed on how to incorporate bank behavior into interbank networks. More precisely, we need to include micro-founded models of bank's dynamic reactions to financial shocks and to changes in regulatory parameters.

The survey concludes with a discussion of the policy relevance of interbank network models with a special focus on macro-prudential policies and monetary policy. Being able to capture heterogeneity and interconnectedness, the network literature can be a useful source for policy insights on financial stability. As data availability improves, it is possible to get increasingly accurate network representations of the underlying financial system. The interbank networks literature focuses on four main policy areas. The first is identifying critical institutions, where measures of centrality and clustering are used to identify the systemically relevant banks in the network. The second policy area we discuss is stress testing and how supervisory authorities can gather insights from network models for stress testing exercises. The third focus is on monetary policy. Central banks are introduced into the interbank network by allowing one bank either to supply an unlimited amount of liquidity or to provide liquidity against eligible collateral. The fourth and most studied area focuses on macro-prudential policy. The theoretical network literature has done policy experiments to simulate the impact of different regulatory measures on systemic risk. More research is needed to evaluate the impact of macro-prudential policy instruments on the banking sector as well as the analysis of the interactions between different macro-prudential policy instruments. Similarly, the evaluation of the interactions between monetary policy and macro-prudential policy is also an interesting topic for further research. 


\title{
Too Interconnected to Fail: A Survey of the Interbank Networks Literature*
}

\author{
Anne-Caroline Hüser ${ }^{\dagger}$
}

First version: December 2014

This version: March 2015

\begin{abstract}
The banking system is highly interconnected and these connections can be conveniently represented as an interbank network. This survey presents a systematic overview of the recent advances in the theoretical literature on interbank networks. We assess our current understanding of the structure of interbank networks, of how network characteristics affect contagion in the banking system and of how banks form connections when faced with the possibility of contagion and systemic risk. In particular, we highlight how the theoretical literature on interbank networks offers a coherent way of studying interconnections, contagion processes and systemic risk, while emphasizing at the same time the challenges that must be addressed before general results on the link between the structure of the interbank network and financial stability can be established. The survey concludes with a discussion of the policy relevance of interbank network models with a special focus on macroprudential policies and monetary policy.
\end{abstract}

Keywords: Interbank networks; systemic risk; contagion; banking; macro-prudential policy

JEL codes: G21; E44; D85; G18; G01

*I am grateful to Iñaki Aldasoro for helpful suggestions and to Ester Faia for introducing me to interbank networks. I gratefully acknowledge research support from the Research Center SAFE, funded by the State of Hessen initiative for research LOEWE.

${ }^{\dagger}$ Goethe University Frankfurt $\mathcal{E}$ SAFE. Email: hueser@safe.uni-frankfurt.de; Address: House of Finance, Goethe University, Theodor-W.-Adorno-Platz 3, 60629 Frankfurt am Main, Germany. 


\section{Contents}

1 Introduction 1

$\begin{array}{lll}2 & \text { Interbank network structure and topology } & \mathbf{7}\end{array}$

2.1 Overview of features particular to interbank networks . . . . . . . . 7

2.2 Selected empirical findings on the structure of interbank networks . . . . . 8

2.2 .1 Degree distribution . . . . . . . . . . . . . . . . . 8

2.2 .2 Core-periphery structures . . . . . . . . . . . . . . . 9

2.3 Multilayer interbank networks . . . . . . . . . . . . . . . . . . . 10

3 Effect of network structure on contagion $\quad 11$

3.1 Direct linkages . . . . . . . . . . . . . . . . . . . . 11

3.1.1 Pioneering works: Are more links always better? . . . . . . . . . 12

3.1.2 Network characteristics and contagion . . . . . . . . . . . . . 15

3.2 Indirect linkages . . . . . . . . . . . . . . . . . . . 16

3.3 Interactions between direct and indirect linkages . . . . . . . . . . . 17

4 Network formation $\quad \mathbf{2 0}$

4.1 Random link formation . . . . . . . . . . . . . . . . . . . . 21

4.1.1 Combining random and strategic network formation . . . . . . . 21

4.1.2 Preferential lending and random link formation . . . . . . . . . . 21

4.2 Strategic network formation . . . . . . . . . . . . . . . . 23

4.3 Network formation games . . . . . . . . . . . . . . . . . . . . . 24

4.4 Endogenous network formation . . . . . . . . . . . . . . 24

5 Policy insights from interbank networks 26

5.1 Identifying critical institutions . . . . . . . . . . . . . 26

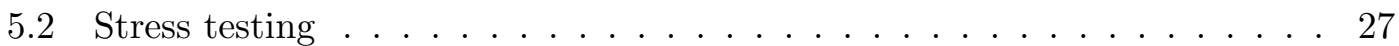

5.3 Insights for monetary policy . . . . . . . . . . . . . . . 28

5.4 Insights for macro-prudential policy . . . . . . . . . . . . . . . . 29

5.4 .1 Liquidity requirements . . . . . . . . . . . . . . . . . . 29

5.4 .2 Limiting counterparty risk . . . . . . . . . . . . . . . . 30

5.4 .3 Capital requirements . . . . . . . . . . . . . . . . . . . 31

6 Conclusion $\quad 32$ 


\section{Introduction}

Why model the banking sector as a network? Banks are highly interdependent, they are connected via both the asset and the liability sides of their balance sheets. Connections can be either direct, indirect or both. Banks are directly connected through mutual exposures acquired on the interbank market. Similarly, banks are indirectly connected through holding similar portfolios of assets. These connections in the interbank market can be conveniently represented as a network. Networks are constituted of nodes and links between these nodes. In the case of interbank networks, the nodes represent banks and the links represent the interbank relations.

Representing the interbank market as a network ${ }^{1}$ allows to model interactions between several heterogeneous financial institutions and thereby improves our understanding of complex economic phenomena such as financial crises. Capturing heterogeneity and interconnections are a welcome addition to the toolbox of researchers in the macro finance area. Indeed, more traditional macro finance models often work with representative banks. This modeling technique has long been criticized for its inability to capture the complexity of the banking sector.

A network approach to banking is particularly important for assessing financial stability and systemic risk (Allen and Babus, 2009; Haldane, 2009). This approach can be instrumental in capturing the externalities that the risk associated with a single institution may create for the entire system. Indeed, from a financial stability perspective, banks should neither be too-big-to-fail nor too-interconnected-to-fail. A better understanding of network externalities may facilitate the adoption of a macro-prudential framework for financial supervision. Network externalities arise when risk-taking behaviour of individual institutions affects other institutions and the system as a whole. To guide policy it becomes necessary, in this context, to measure the systemic importance of individual banks, i.e. their capacity to generate contagion in the rest of the system. ${ }^{2}$ The analysis of interbank networks can provide this guidance.

In their survey on systemic risk in banking De Bandt et al. (2012) put forward a 'financial fragility hypothesis', arguing that systemic risk and potential contagion effects are of special concern in the financial system. They highlight three interrelated features that provide a basis for the 'financial fragility hypothesis'. This survey argues that these three features can all be captured by interbank network models, making these models particularly appealing for financial stability research. One feature that makes the financial system fragile according to De Bandt et al. (2012) is that there is a 'complex network of exposures among banks'. Interbank network models are clearly able to capture these exposures and they do so at increasing levels of complexity, representing different maturities and instruments at the same time (Aldasoro and Alves, 2015; Langfield et al., 2014; Montagna and Kok, 2013) and including several contagion channels (Gai and Ka-

\footnotetext{
${ }^{1}$ For an overview of the application of network analysis to other social and economic contexts, we refer the interested reader to a book chapter by Lee (2010) or to the textbooks by Jackson (2010) and Goyal (2012).

${ }^{2}$ For a discussion on the relationship between network externalities and systemic risk, see Aldasoro and Angeloni (2015).
} 
padia, 2010; Glasserman and Young, 2014). The second feature that leads to a fragile financial system is that the maturity transformation activity performed by banks makes the structure of the bank's balance sheet matter. This makes miscoordination of depositors and creditors costly. Network studies have analyzed these problems, for example by studying bank runs (Dasgupta, 2004), short-term lending (Battiston et al., 2012a), maturity transformation (Georgescu, 2015) and rollover risk (Anand et al., 2012; Allen et al., 2012). Interbank network models also incorporate the balance sheet structures of banks at increasing levels of sophistication. Recent models feature banks optimizing their balance sheet and thereby endogenously creating the interbank network (Bluhm et al., 2014a; Georg, 2013). The third and last feature highlighted by De Bandt et al. (2012) is the 'informational and control intensity of financial contracts, which rely on promises and expectations about future payments'. The role of uncertainty (Caballero and Simsek, 2013), increasing counterparty risk (Hałaj and Kok, 2015) and liquidity hoarding (Aldasoro et al., 2015; Gai et al., 2011) can all be explored in interbank network models. Hence the interbank network literature can help understand systemic risk in all its facets and can therefore be relevant not only for academic research but also for practitioners.

This survey reviews the literature on interbank networks, which is part of a growing literature on financial networks. The broader financial networks literature is analyzing connections between financial institutions: banks, but also hedge funds, insurance companies, etc. ${ }^{3}$ We restrict the survey's focus to the interbank network literature and take stock of our current understanding of the topology of interbank networks, of how its structure affects contagion and of how banks form connections when faced with the possibility of contagion and systemic risk. For each aspect we provide a brief overview of the results and highlight avenues for further research. A final section reviews and discusses the policy insights gained from the interbank networks literature.

The first section of this survey reviews empirical work, which provides a direct insight into the topology of real interbank networks. ${ }^{4}$ The structural features of the banking system can be particularly well captured by a network representation. The network is able to represent the fact that banks have heterogeneous balance sheet characteristics. Networks can also capture that links between banks are directed, since it is economically meaningful whether a bank borrows from or lends to another bank. Furthermore, networks also allow for weighted links between banks, where the weights are the monetary quantities that banks exchange. Finally, a network representation can also incorporate the different types of links between banks. As Langfield and Soramäki (2014) highlight, banks engage in hundreds of different types of transactions with each other, such as interbank lending, repurchase agreements or derivatives. This plethora of possible link types can be captured by multilayer financial networks, where different layers represent different transaction types (Aldasoro and Alves, 2015; Bargigli et al., 2014; Langfield et al., 2014; Montagna and Kok, 2013). Empirical studies have also provided new insights into the structure of interbank networks. A major result is that interbank networks exhibit

\footnotetext{
${ }^{3}$ See for example Billio et al. (2012).

${ }^{4}$ See Langfield and Soramäki (2014) for a survey of this empirical work.
} 
a core-periphery structure with a highly connected core and few connections to and among periphery banks (Craig and von Peter, 2014; Fricke and Lux, 2015a; Langfield et al., 2014).

Empirical network studies form a vital basis for simulation studies ${ }^{5}$. They also deliver valuable stylized facts and structural features for theoretical modeling, hence their relevance for this survey. Yet by construction, empirical studies are unable to draw conclusions on the generic relationship between contagion risk and the characteristics of the financial system. This is the gap theoretical modeling can fill.

The second section of this survey discusses the theoretical literature on the effect of network characteristics on the process of contagion. ${ }^{6}$ The literature covered in this section is characterized by two features. The first is that it analyzes network dynamics generated by subjecting the network structure to a shock. The second feature is that these dynamics take place on an exogenously given and static network structure. Links between banks can be either direct, indirect or both.

Links created via the interbank market are said to be direct. Upper (2011) has highlighted that we never have observed a bank failure due to losses on the interbank market. The vast majority of empirical financial network simulation studies find little potential for failures resulting from direct interbank linkages (Summer, 2013; Upper, 2011). Cifuentes et al. (2005) argue that these simulation results are hardly surprising, since interbank loans represent a limited fraction of bank balance sheets. There are other explanations as to why we never have observed a default due to losses on the interbank market. Maybe government interventions have prevented contagion via this channel. ${ }^{7}$ Government bail-outs are undesirable for moral-hazard reasons, hence studying how to limit contagion before it occurs is worthwhile. Another argument for studying direct exposures is that the fear of direct contagion on the interbank market can trigger indirect contagion. Models show that the fear of losses in the interbank market may trigger bank runs (Dasgupta, 2004), mark-to-market losses from perceived credit quality deterioration (Glasserman and Young, 2014), confidence crises (Arinaminpathy et al., 2012; May and Arinaminpathy, 2009), gridlocks (Freixas et al., 2000) or it may worsen indirect contagion (Caccioli et al., 2015). It is therefore important to understand the working of the direct channel before exploring its potential interactions with other channels of contagion. The literature has also analyzed indirect linkages between banks. Connections studied include models with cross-holdings of shares (Elliott et al., 2014), multiple assets (Caccioli et al., 2014) and linked portfolio returns (Lagunoff and Schreft, 2001).

Research questions in the theoretical literature on the direct and indirect channel are strongly related. They study how the network structure and the nodes' characteristics influence contagion. Relevant characteristics of the network topology are the level of connectivity, diversification, integration and the size of interbank exposures. Important bank level characteristics are, among others, leverage and net worth.

\footnotetext{
${ }^{5}$ See Upper (2011) and Summer (2013) for surveys.

${ }^{6}$ For general results about network structure and cascading failures, see for example Blume et al. (2011).

${ }^{7}$ See Laeven and Valencia (2013) for policy responses to banking crises from 1970 to 2011.
} 
Real-world banks have however both direct and indirect links at the same time. Combining direct and indirect links in an interbank network not only shows how shocks are propagated, but is also able to capture how shocks are amplified (Cifuentes et al., 2005). The amplification mechanism in these models is mainly driven by fire sales and resulting endogenous changes in asset prices. Caccioli et al. (2015) show that the interaction between the direct and indirect contagion channels is very important, creating risks that may be much larger than any single channel of contagion alone. From a risk perspective, these models interact counterparty risk resulting from direct exposures with liquidity risk resulting from the fire sales channel. ${ }^{8}$

The theoretical literature has generated a number of general results on the effect of the network structure on contagion. A first result is that the number and magnitude of defaults depend on the network topology. There is now substantial research characterizing those structures that tend to propagate default or alternatively that tend to dampen it (Allen and Gale, 2000; Acemoglu et al., 2015; Freixas et al., 2000; Gai et al., 2011; Nier et al., 2007). An avenue for further research is to have more realistic network structures on which to analyze contagion. Since empirical studies now provide an increasing number of stylized facts on the interbank network topology, research needs to move beyond deriving results on random networks or on overly simplified structures ${ }^{9}$. Furthermore, the fragility of the system depends on the location in the network of the institution that was initially affected (Gai and Kapadia, 2010). Intuitively, the failure of core banks is more damaging than the failure of a periphery bank. Finally, another main finding is that there is a trade-off between risk sharing via linkages to other banks and contagion risk due to too many linkages. While the existence of the trade-off is not disputed, there is no consensus on whether a complete network dampens (Allen and Gale, 2000; Freixas et al., 2000) or fuels contagion (Battiston et al., 2012b; Vivier-Lirimont, 2006). Some studies argue that intermediate levels of connectivity are better, for example because the effect of connectivity on contagion is non-monotonic (Gai et al., 2011; Nier et al., 2007). Recent research by Acemoglu et al. (2015) argues that a complete network is more resilient to small shocks whereas in the presence of large shocks, less connections are better able to prevent contagion. The lack of consensus hinges on the fact that these studies have been conducted on widely different network structures and under different assumptions about the size and type of shocks. ${ }^{10}$ Again, conducting analyses on more realistic network structures is required to make a convincing case. The question that remains is how banks strategically trade off risk sharing and contagion risk. This topic has been taken up recently by the literature on network formation.

The third section argues that one limitation of static models of financial networks is that they do not provide an account of link formation. More precisely, they do not model the dynamic process by which financial institutions enter into obligations to one another

\footnotetext{
${ }^{8}$ This confirms results of more traditional macro finance models by Geanakoplos (2010) and Brunnermeier and Pedersen (2009) that market liquidity and funding liquidity are mutually reinforcing and their interaction can lead to liquidity spirals.

${ }^{9}$ Prominent structures include the complete network, the star network and the ring network.

${ }^{10}$ See Table 2 in the appendix for an overview of the different types of shocks and network structures used in this literature.
} 
in the first place. ${ }^{11}$ So far, three main approaches to link formation have crystallized in the financial networks literature. One branch of the literature borrows ideas from network growth models. Typically, these are random network models where new nodes are born over time and form attachments to existing nodes when they are born. ${ }^{12}$ One option is to generate links with a certain probability or according to a stochastic process (Anand et al., 2012). Another option is to condition link formation on characteristics of the nodes, such as their profits (Lenzu and Tedeschi, 2012) or their willingness to extend an interbank loan (Lux, 2014). This process of network formation is called preferential attachment. Trust is an important element in this process of link formation, a result also confirmed by the empirical literature on relationship lending (Affinito, 2012; Bräuning and Fecht, 2012; Cocco et al., 2009).

A second area uses strategic network formation, where banks assess the costs and benefits from forming a link with another bank (Blume et al., 2013). A prominent theme in strategic network formation are rollover decisions by banks, often modeled using global games techniques. Creditors strategically decide to rollover a loan after receiving a signal about the solvency or performance of the borrower (Allen et al., 2012; Anand et al., 2012; Fique and Page, 2013). Closely related to strategic network formation are network formation games. A game of network formation specifies a set of players, the link formation actions available to each player and the payoffs to each player from the networks that arise out of individual linking decisions. Rollover decisions (Fique and Page, 2013) or decisions to enter preferential trading relationships in an interbank market (In't Veld et al., 2014) have been modeled as network formation games.

The third branch of this literature uses endogenous network formation. Banks choose the amount of interbank lending and/or borrowing by optimizing their (heterogeneous) balance sheets (Aldasoro et al., 2015; Bluhm et al., 2014b; Georg, 2013; Hałaj and Kok, 2015) and thereby create the structure of the interbank network. The literature on endogenous network formation combines economic modeling techniques with the insight that interconnections need to be taken seriously.

Representing the banking system as a network is arguably more realistic than to model it as a representative bank, as traditional macro finance models do. Being able to capture heterogeneity and interconnectedness, the network literature can be a useful source for policy insights on financial stability. As data availability improves, it is possible to get increasingly accurate network representations of the underlying financial system. It is important that the theoretical literature takes better account of the achievements in the empirical literature, so that models become more realistic and we are able to derive general results on contagion of relevance to policy-makers.

The interbank networks literature focuses on four main policy areas. The first is identifying critical institutions, where measures of centrality and clustering are used to identify the systemically relevant banks in the network. ${ }^{13}$ The second policy area we discuss is stress testing and how supervisory authorities can gather insights from network

\footnotetext{
${ }^{11}$ See Jackson (2005) for a survey on network formation models in economics.

${ }^{12}$ See chapter five on growing random networks in Jackson (2010).

${ }^{13}$ See Langfield and Soramäki (2014) for a survey of these measures.
} 
models for stress testing exercises (Anand et al., 2014a; Canedo and Jaramillo, 2009; Chan-Lau et al., 2009; Espinosa-Vega and Solé, 2014; Hałaj and Kok, 2015). The third focus is on monetary policy. Central banks are introduced into the interbank network by allowing one bank either to supply an unlimited amount of liquidity (Bluhm et al., 2014b) or to provide liquidity against eligible collateral (Georg, 2013). The final and most studied area focuses on macro-prudential policy. The theoretical network literature has done policy experiments to simulate the impact of different regulatory measures on systemic risk (Aldasoro et al., 2015; Gai et al., 2011; Hałaj and Kok, 2015; Haldane and May, 2011; Nier et al., 2007).

After having briefly discussed the literature reviewed in this survey, let us now turn to an overview of the already existing surveys of the field. Considering the growing body of theoretical literature on financial networks, there have been remarkably few surveys on the subject. An early survey by Allen and Babus (2009) discusses the then emerging literature on financial networks as well as the methodologies used and makes a case why the complexity of financial systems can be 'naturally captured' using a network representation. Yet, since 2009, the theoretical literature has tremendously expanded and to the best of our knowledge, no survey has recently taken stock of these new studies. ${ }^{14}$ Four recent surveys are mainly focused on simulations of contagion in financial networks and their applications. Upper (2011) reviews simulation methods to test for contagion in empirical interbank networks as well as methods to construct interbank networks from different data sources. Elsinger et al. (2013) also survey simulated empirical financial networks and their applications in systemic risk analysis. They describe in detail how such simulations are designed and thereby nicely complement the slightly less technical survey of these methods by Upper (2011). Langfield and Soramäki (2014) review the empirical literature related to interbank markets from a systemic risk perspective. In addition to discussing network simulations, they also survey the literature on the topology of empirical interbank networks, as well as the literature for identifying systemically important banks. The survey by Summer (2013) also focuses on simulation studies.

The present survey aims to fill this gap by providing a systematic overview of the theoretical interbank network literature. Table 2 in the appendix classifies the theoretical interbank network literature by link type, shock type, loss propagation as well as by network formation process and network structure. The survey also provides a systematic discussion of the policy insights from theoretical network models. The survey is intended to be relevant not only for academic economists, but also for financial stability experts at central banks or supervisory authorities interested in the progress of the field and its potential policy relevance. Finally, this survey also builds a bridge between results from the financial network literature and the established macro finance literature. ${ }^{15}$ Modeling techniques clearly differ. Network analysis can easily capture heterogeneity

\footnotetext{
${ }^{14}$ Roughly half of the hundred papers referenced here were published in 2013, 2014 or 2015. Another indicator of the increasing use of network analysis is the recent creation of the 'Journal of Network Theory in Finance' (http://www.risk.net/type/journal/source/journal-of-network-theory-in-finance).

${ }^{15}$ For an overview of the macro finance literature see for example the survey by Brunnermeier et al. (2013) or by Shin (2010). For a comprehensive collection of classic articles and recent contributions on liquidity and crises, see Allen et al. (2011).
} 
and interconnections, whereas the incorporation of optimizing financial institutions into networks is still in its infancy. The established macro finance literature can build on a long tradition of economic modeling of agent's decisions, with the restriction that agents are often representative. Still, both share similar research topics, for example the study of the propagation and amplification of shocks in the financial system, fire sales spirals, market liquidity or the fragility of financial intermediaries.

This survey is structured as follows. The next section takes stock of our current understanding of the topology of interbank networks. The third section reviews how the structure of the interbank network affects contagion. The fourth section analyzes how banks form connections when faced with the possibility of contagion and systemic risk. The fifth section reviews the policy insights gained from the interbank networks literature. The final section concludes by highlighting a few avenues for further research.

\section{Interbank network structure and topology}

Empirical work provides a direct insight into the topology of real interbank networks. Table 1 in the appendix classifies the empirical literature on the topology of interbank networks by the scope of the interbank market and the data type used. It also summarizes topological features of these interbank markets. The studies reviewed below also deliver valuable stylized facts and structural features for theoretical modeling. Furthermore, the specific characteristics of interbank networks have implications for the design of policy responses to financial turmoil (Haldane and May, 2011).

\subsection{Overview of features particular to interbank networks}

The structural features of the banking system can be captured particularly well by a network representation. First, the network is able to represent the fact that banks have heterogeneous balance sheet characteristics. Banks will be of different sizes and have different compositions of assets and liabilities. Heterogeneous balance sheet characteristics imply heterogeneity in banks' inherent ability to withstand external shocks. Second, networks can also capture that links between banks are directed. Consider the simplest case where one bank lends to another bank. The first bank is exposed to the default of the second bank (counterparty risk), while the second bank might be exposed to the willingness of the first bank to rollover the loan (rollover risk). In both cases, the direction of the link does matter for economic interpretation. Third, networks also allow for weighted links between banks. A weighted link in this context means that links are associated with monetary quantities and transaction volumes. For example a weighted link between two banks can represent the size of the interbank loans between those two banks. Finally, a network representation can also incorporate the different types of links between banks. As Langfield and Soramäki (2014) highlight, banks engage in hundreds of different types of transactions with each other, including many variations on deposits; prime lending; repurchase agreements; and derivatives. This plethora of possible link types is now captured by recent research on multilayer financial networks 
(Aldasoro and Alves, 2015; Bargigli et al., 2014; Langfield et al., 2014; Montagna and Kok, 2013). In addition, banks are connected by virtue of their exposures to common risk factors. Banks are also connected across borders, but cross-border exposures are hard to quantify due to scarce data. Recent efforts have been directed for example at studying global banking from a network perspective (Garratt et al., 2014; Minoiu and Reyes, 2013) and at analyzing how international linkages in interbank markets affect the stability of interconnected banking systems (Tonzer, 2015).

The overall structure of interbank networks exhibits high clustering coefficients ${ }^{16}$. Real-world interbank networks are also sparse, which means that only a small fraction of all possible links do actually exist. The distribution of the number of connections of each node appears to be fat-tailed, meaning that few nodes have many links and many nodes have few links. Interbank networks have also been found to be small worlds ${ }^{17}$ and to show disassortative mixing with respect to the bank size, so small banks tend to trade mainly with large banks and vice versa. ${ }^{18}$

\subsection{Selected empirical findings on the structure of interbank networks}

\subsubsection{Degree distribution}

The first selected feature is the degree distribution of the nodes. The degree is the number of (incoming and/or outgoing) connections per node, i.e. the number of the bank's counterparties. Boss et al. (2004) are the first to provide an empirical analysis of the structural features of a real-world interbank network using network theory. They analyze the Austrian interbank market based on central bank data. Their main finding is that the network structure of the interbank market is scale free ${ }^{19}$. This implies that there are very few banks with many interbank linkages, whereas there are many banks with only a few links.

Many other existing interbank networks have been reported to resemble scale-free networks, such as the European interbank market for large banks (Alves et al., 2013), the Italian interbank market (De Masi et al., 2006), the Colombian payment and settlement systems (Léon and Berndsen, 2014) as well as the US Fedwire system (Soramäki et al., 2007).

Other studies by Bech and Atalay (2010), Iori et al. (2008) and Fricke and Lux (2015b) have nuanced these results. Studying the US Federal Funds market, Bech and Atalay (2010) have also found that the number of counterparties per bank follows a fat-tailed distribution, with most banks having few counterparties and a small number

\footnotetext{
${ }^{16}$ Clustering coefficients measure the tendency of linked nodes to have common neighbours.

${ }^{17}$ Small world networks have two main features: small average shortest path length and a clustering coefficient significantly higher than expected by random chance, see Watts and Strogatz (1998).

${ }^{18} \mathrm{~A}$ characteristic which is related to the core periphery structure of interbank networks as highlighted by Craig and von Peter (2014).

${ }^{19} \mathrm{~A}$ scale-free network is a network in which the fraction of nodes with degree $k$ is proportional to $k^{-\alpha}$, where $\alpha$ is the so-called scaling parameter. In other words, scale-free networks exhibit a power law distribution of degrees. The term scale-free indicates that there is no typical scale of the degrees, i.e. the mean may not be representative.
} 
having many. However, the degree distribution is not necessarily best represented by a power law distribution. While the power law distribution provides the best fit for the out-degree, the negative binomial distribution provides the best fit for the in-degree. Iori et al. (2008) and Fricke and Lux (2015b) find no evidence in favor of scale-free networks in the e-MID market. Rather, Fricke and Lux (2015b) find that the data are best described by negative binomial distributions. Iori et al. (2008) find that the degree distribution, though not scale-free, is still heavier tailed than a purely random network ${ }^{20}$.

In view of the mixed evidence regarding the power-law behavior, it is not settled whether real-world interbank networks fall into the category of scale-free networks. Knowing the degree distribution of interbank networks is crucial for policy design. As Albert et al. (2000) point out, scale-free networks are relatively robust to the random breakdown of nodes. At the same time, the system is very vulnerable to the risk of the specific removal of hubs, which can even lead to its collapse. This characteristic has been coined robust-yet-fragile (Haldane, 2009), indicating that random disturbances are easily absorbed (robust) whereas targeted attacks on the most central nodes may lead to a breakdown of the entire network (fragile). If interbank networks are scale-free, then identifying the vulnerable nodes is a key policy objective.

Thus, taking into account the relevance of such topological features, a more rigorous statistical analysis of the distributional properties of interbank network data should be worthwhile. It crucially hinges on the improved availability of more granular data. Of further interest are also the policy implications. For example, what does it mean for network stability to have a degree distribution that follows a negative binomial distribution? So far, the empirical literature has been silent on these questions.

\subsubsection{Core-periphery structures}

Numerous empirical studies find that interbank markets have a core-periphery structure: Germany (Craig and von Peter, 2014), the e-MID ${ }^{21}$ (Iori et al., 2008; Fricke and Lux, 2015a), the UK (Langfield et al., 2014), the US federal funds market (Bech and Atalay, 2010) and the US Fedwire system (Soramäki et al., 2007). The core-periphery structure is sometimes also called tiered or hierarchical structure in the network context.

Craig and von Peter (2014) capture this market structure by formulating a coreperiphery model and devise a procedure for fitting the model to real-world networks. The banks in the system are partitioned into two sets based on their bilateral relations with each other: core banks lend to each other; periphery banks do not lend to each other; core banks lend to periphery banks; core banks borrow from periphery banks. Craig and von Peter (2014) argue that tiering is founded on an economic concept that is central to banking, namely intermediation. Core banks are special intermediaries that play a

\footnotetext{
${ }^{20} \mathrm{~A}$ random network is a network whose links are formed according to a random process. Such random networks are a useful benchmark against which we can contrast observed networks; such comparisons help to identify which elements of the interbank structure are not the result of mere randomness, but must be traced to other factors.

${ }^{21}$ The e-MID is an electronic trading system for unsecured deposits based in Milan and mainly used by Italian banks for overnight interbank credit.
} 
central role in holding together the interbank market. The interbank market is often modeled in the theoretical banking literature as a centralized exchange in which banks smooth liquidity shocks (Ho and Saunders, 1985; Bhattacharya and Gale, 1987; Freixas and Holthausen, 2005). Craig and von Peter (2014) show that the interbank market looks very different from traditional banking models. The market is not a centralized exchange. It is in fact a sparse network, centered around a tight set of core banks that intermediate between numerous smaller banks in the periphery. Furthermore, this hierarchical structure is highly persistent over time (Craig and von Peter, 2014; Fricke and Lux, 2015a).

Theoretical models of the interbank market show the emergence of a core-periphery structure where banks form credit relationships based on trust in other banks (Lenzu and Tedeschi, 2012) or based on their willingness to lend (Lux, 2014). In't Veld et al. (2014) show that a core periphery network structure can form endogenously in a network formation game if agents are heterogeneous. ${ }^{22}$

\subsection{Multilayer interbank networks}

The vast majority of empirical financial networks papers studies the overnight interbank market. Yet this is just one type of relation between banks out of a multiplicity of transactions that banks engage in. Recent empirical studies hence argue that a more realistic representation of the interbank market is a multiplex, or multilayer network. A multilayer network is composed by a series of layers. Each node is a bank and each layer is a network representing one type of relation. Layers can represent maturity, nature of the contract (secured versus unsecured), instruments, direct and indirect links. This type of analysis crucially hinges on the availability of granular data. The main takeaway at this stage is that it is important to differentiate the layers of the network, since both topology and contagion processes can be different across layers.

Bargigli et al. (2014) exploit a database of supervisory reports on Italian banks that includes all bilateral exposures broken down by maturity and by the secured and unsecured nature of the contract. They find that layers have different topological properties and persistences over time. The topology of the total interbank market is closely mirrored by the one of the overnight market, while both are little informative about other layers. In general, the presence of a link in a layer is not a good predictor of the presence of the same link in other layers.

Langfield et al. (2014) construct two networks from UK data: one based on multiple layers of exposures, by aggregating banks' counterparty credit risks; and another based on multiple layers of funding, by aggregating banks' funding from other banks. They find that these two networks have different structural characteristics. Structural differences suggest that credit risk and liquidity risk propagate in the interbank system by different contagion processes.

\footnotetext{
${ }^{22}$ See also Fricke and Lux (2015a) and Langfield et al. (2014) for a further discussion on why such core-periphery structures may emerge in interbank markets.
} 
Montagna and Kok (2013) develop an agent-based model with the aim of catching risks arising from different banks' businesses based on a data set featuring large EU banks. The interbank market is represented as a multilayered network that takes into account long- and short-term bilateral exposures and common exposures to external financial assets. The authors find that focusing on a single interbank segment can underestimate the likelihood of contagion: the interaction among layers may amplify contagion risk in those cases where certain institutions are systemically relevant across different segments. Aldasoro and Alves (2015) also use data on exposures between large European banks. The data set is broken down by both maturity and instrument type to characterize the main features of the multiplex structure of the network of large European banks. This multiplex network presents a high similarity between layers, stemming both from standard similarity analyses as well as a core-periphery analysis of the different layers.

To conclude this section on empirical network studies, it is important to highlight that this literature analyzes the interbank network structure for particular countries. They provide valuable insights into topological features of real-world networks: realistic degree distributions, core-periphery structures, characteristics across maturities and instrument types... Hence they form a vital basis for simulation studies and deliver valuable stylized facts and structural features for theoretical modeling. Yet by construction, empirical studies are unable to draw conclusions on the generic relationship between contagion risk and the characteristics of the financial system. This is the gap theoretical modeling can fill.

\section{Effect of network structure on contagion}

This section discusses the theoretical literature on the effect of the network structure on the contagion process. ${ }^{23}$ The literature covered in this section is characterized by two features. The first is that it analyzes network dynamics generated by subjecting the network structure to a shock. The second feature is that these dynamics take place on an exogenously given and static network structure.

\subsection{Direct linkages}

In the real world, no bank ever failed because of losses on the interbank market (Upper, 2011). One possibility is therefore that the channel is irrelevant. Several studies ${ }^{24}$ have estimated the matrix of bilateral exposures among banks in advanced economies and simulated the extent of contagion following a single bank failure. These studies find little potential for failures resulting from direct interbank linkages. However, these authors assume a fixed structure of interbank claims and use estimation methods ${ }^{25}$ that

\footnotetext{
${ }^{23}$ For general results about network structure and contagion, see for example Blume et al. (2011).

${ }^{24}$ Among others, Sheldon and Maurer (1998), Furfine (2003), Upper and Worms (2002), and Wells (2002) estimate the matrix of bilateral exposure among banks for Switzerland, the U.S., Germany and the U.K., respectively. See Upper (2011) for a survey on the results of the network simulation literature.

${ }^{25}$ The most widely used estimation method is maximum entropy, which distributes interbank exposures as evenly as possible among the nodes. Mistrulli (2011) shows that for the Italian banking system the
} 
create unrealistically dense networks, and therefore fail to capture all of the dynamics. ${ }^{26}$ There are other explanations as to why we never have observed a default due to losses on the interbank market. Maybe government interventions have prevented contagion via this channel. ${ }^{27}$ Government bail-outs are undesirable for moral-hazard reasons, hence studying how to limit contagion before it occurs is worthwhile. Another argument for studying direct exposures is that the fear of direct contagion on the interbank market can trigger indirect contagion. Models show that the fear of losses in the interbank market may trigger bank runs (Dasgupta, 2004), mark-to-market losses from perceived credit quality deterioration (Glasserman and Young, 2014), confidence crises (May and Arinaminpathy, 2009; Arinaminpathy et al., 2012) or gridlocks (Freixas et al., 2000). It is therefore important to understand the working of the direct channel before exploring its potential effects on other channels of contagion.

\subsubsection{Pioneering works: Are more links always better?}

Pioneering theoretical works by Allen and Gale (2000) and Freixas et al. (2000) suggest that a highly connected interbank network enhances the resilience of the system to the insolvency of an individual bank. Allen and Gale (2000) set up a basic network structure involving four banks. Because liquidity preference shocks are imperfectly correlated across regions, banks hold interregional claims on other banks to provide insurance against liquidity preference shocks. Allen and Gale (2000) demonstrate that the spread of contagion depends crucially on the pattern of interconnectedness between banks. When the network is fully connected (the authors call it 'complete' network) the amount of interbank deposits held by any bank is evenly spread over all other banks. In such a setting, the impact of a shock is dampened since every bank takes a small loss and there is no contagion. By contrast, when the network structure is a ring (each node has one inand one out-going link, Allen and Gale (2000) call it 'incomplete' network), the system is more fragile. The initial impact of a shock is concentrated among neighboring banks. Once these default, the early liquidation of long-term assets and the associated loss of value propagate contagion to previously unaffected banks. The possibility of contagion hence depends strongly on the structure of links in the network. The main insight is that the complete claims structure is more robust than the incomplete structure. While the study by Allen and Gale (2000) provides valuable insights into the stability of interbank markets, their model has only four banks and both the network structures employed and the financial structure of banks are too simplistic to be sure that the intuitions generalize to real-world financial systems.

use of maximum entropy techniques underestimates contagion risk relative to an approach that uses information on actual bilateral exposures. See Elsinger et al. (2006) for an exposition of the maximum entropy technique and a discussion. Alternative estimation methods, such as minimum density (Anand et al., 2014b), are currently being developed. The best solution would be to have data on bilateral exposures of banks so as to skip the estimation step altogether.

${ }^{26}$ The next section will show that adding indirect linkages via common assets of banks will lead to substantially different simulation results. Notably Cifuentes et al. (2005) show that when the prices of fire sold assets are allowed to change endogenously, the impact of an initial shock may be considerable.

${ }^{27}$ See Laeven and Valencia (2013) for policy responses to banking crises from 1970 to 2011. 
While in Allen and Gale (2000) there is uncertainty about the timing of deposit withdrawals à la Diamond and Dybvig (1983), in Freixas et al. (2000) there is uncertainty about the location of deposit withdrawals. Interbank connections enhance the resilience of the system to withstand the insolvency of a particular bank, because a proportion of the losses on one bank's portfolio is transferred to other banks through the interbank agreements. Hence a dense network can be desirable.

Several studies build on the stylized model by Allen and Gale (2000). Leitner (2005) develops a more general framework where the project of an agent can succeed only if he and all the agents to whom he is linked make a minimum level of investment in their projects. This setting can be applied to the slightly more complex set-up of Allen and Gale (2000). Investing in a project then means meeting demand for liquidity by early consumers, and success of the project is equivalent to not going bankrupt. In Leitner (2005), endowments are random variables, therefore an agent may not have enough cash to make the necessary investment. When agents are not linked to one another, agents who realize high endowments have no incentive ex post to help those who realize low endowments. Thus, some positive net present value investments do not take place (or in Allen and Gale (2000)'s setting, some banks that are solvent but illiquid go bankrupt). On the other hand, when agents are linked to one another, agents with high endowments are willing to bail out those with low endowments. The reason is that if they do not, all projects fail by contagion. Linkages may also be optimal ex ante because they allow banks to obtain some mutual insurance even though formal commitments are impossible. Leitner (2005) also characterizes the optimal network size: a more dense network is desirable because it enables a higher level of investment and provides insurance.

Dasgupta (2004) is also interested in the optimal network size. Banks are linked via cross-holdings of deposits, as in Allen and Gale (2000), except that only two regions with a bank each are considered. Depositors receive a private signal about the fundamentals of the bank in their region and choose whether to run or not. Using global games, Dasgupta (2004) is able to isolate a unique equilibrium depending on the value of fundamentals and to determine optimal cross-holdings of deposits.

Brusco and Castiglionesi (2007) study the propagation of financial crises among regions in which banks are protected by limited liability and may invest in an excessively risky asset. Banks are linked via cross-holdings of deposits, as in Allen and Gale (2000). Contrary to the pioneering model, Brusco and Castiglionesi (2007) find that the extent of contagion is greater the larger the number of interbank deposit cross-holdings. A ring network is less conducive to contagion than a complete market structure, which is the opposite result compared to Allen and Gale (2000).

What drives these differing results? The crucial transmission channel in Allen and Gale (2000) is the unexpected early liquidation of the long-term asset due to a liquidity shock, which may induce bank runs and fire sales, which spread the crisis. Early liquidation is not a relevant mechanism in Brusco and Castiglionesi (2007), since contracts can be written contingent on liquidity shocks. The only noncontractible source of contagion, is the return on an excessively risky asset. A bank fails if the highly risky investment fails. Financial crises spread directly, when a failing bank is unable to pay debts to other 
banks. Thus, more contacts among banks increase the probability of contagion.

Vivier-Lirimont (2006) also finds that the higher network density, the larger is the number of banks involved in the contagion process, and the quicker is the contagion phenomenon. Similarly, Battiston et al. (2012b) argue that due to a positive feedback loop resulting from a financial acceleration mechanism, more connections lead to greater fragility in the financial system. This paper shows that a financial network can be most resilient for intermediate levels of risk diversification.

Nier et al. (2007) study the effect of contagion after an idiosyncratic shock to one bank in a random network. They find that the effect of connectivity is non-monotonic. For low levels of connectivity, a small increase in connectivity increases the contagion effect. This result is confirmed by Blume et al. (2013), who show that very small amounts of overlinking can have a strong impact on contagion. Furthermoe, Nier et al. (2007) show that for higher density levels, more links improve the ability of a banking system to absorb shocks. Cifuentes et al. (2005) show that in an interbank network connected both directly and indirectly via portfolio holdings, contagion is small either in a complete network or in one with no connections.

Taken together, the previous studies present mixed evidence for the result by Allen and Gale (2000) and Freixas et al. (2000) that complete networks are more resilient than incomplete ones. A recent study by Acemoglu et al. (2015) tries to reconcile these differing perspectives by looking at phase transitions depending on connectivity and shock size. Focusing on regular financial networks ${ }^{28}$, Acemoglu et al. (2015) show that when the magnitude and the number of negative shocks are below certain thresholds, a result similar to that of Allen and Gale (2000) and Freixas et al. (2000) holds: a more equal distribution of interbank linkages leads to a less fragile financial system. This small shock regime requires the size of the negative shock to be less than the total excess liquidity available to the financial network as a whole. In particular, the complete financial network is the configuration least prone to contagious defaults due to more distributed risk sharing. As the magnitude or the number of negative shocks exceed the surplus liquidity in the financial system, more financial interconnections are no longer a guarantee for stability. Rather, interbank linkages facilitate financial contagion and create a more fragile system. In the presence of large shocks, weakly connected financial networks ${ }^{29}$ are significantly less fragile than more complete networks. The intuition underlying such a sharp phase transition is that, with large negative shocks, the surplus liquidity of the banking system may no longer be sufficient for absorbing the losses. Under such a scenario, less interbank connections guarantee that the losses are shared with the senior creditors of the distressed banks, and hence, protecting the rest of the system.

\footnotetext{
${ }^{28}$ They define a regular network as one in which the total claims and liabilities of all banks are equal.

${ }^{29}$ Acemoglu et al. (2015) suggest a network consisting of a collection of pairwise connected banks with only a minimal amount of shared assets and liabilities with the rest of the system.
} 


\subsubsection{Network characteristics and contagion}

The research prompted by the works of Allen and Gale (2000) and Freixas et al. (2000) has evolved beyond the trade-off regarding density and resilience. Networks have indeed more features than just their level of connectivity. Examples of such characteristics of financial networks are: the size of interbank exposures, leverage, the degree of concentration of the system and balance sheet characteristics.

Gai and Kapadia (2010) make two crucial points. ${ }^{30}$ The first is that rare shocks can have extreme consequences for the interbank network when they occur. The second is that a shock of a given size can have very different impacts depending on which node in the network is hit. The intuition behind these results is that increased connectivity and risk sharing may lower the probability of contagious default, but conditional on a failure, more connections also allow contagion to spread further. This a variant of the robust-yet-fragile tendency of financial networks.

Gai et al. (2011), building on Gai and Kapadia (2010), construct an interbank network of 250 banks subject to funding liquidity shocks ${ }^{31}$. Banks hold both unsecured interbank liabilities and repo liabilities on their balance sheet. They simulate different shock scenarios. The simulation stops when no new banks are forced into liquidity hoarding or until every bank is hoarding. They design a baseline scenario in which the links connecting banks are distributed roughly uniformly (Poisson). They study what happens when a random adverse haircut shock at one bank forces it to start hoarding liquidity. They study the frequency and contagious spread of systemic liquidity crises, identifying the tipping point in the process. Contagion occurs for average degrees between 0 and 20 and its probability is non-monotonic in connectivity, at first increasing before falling. An average degree of 7.5 is identified as tipping point from which the probability of contagion starts falling from close to one. ${ }^{32}$

Nier et al. (2007) construct an interbank network as a random graph. They model the number of defaults in an interbank market of 25 banks depending on the probability of connectedness and the net worth of the bank. For an average degree of 7.5 (which corresponds to a 30 percent probability of connectedness) Nier et al. (2007) find that the number of defaults tumbles from five to zero for a net worth of three percent. Interestingly, although the compared networks widely differ in size, the average degree seems to matter more as indicator of a tipping point.

To assess the role of concentration, Gai et al. (2011) study how the results change under a fat-tailed (geometric) network configuration, where some banks in the network are much more highly connected than the typical bank. This leads to a tiered structure. Contagion is less severe and less likely for low average degrees than under the Poisson distribution. This reflects the well-know result by Albert et al. (2000) that fat-tailed networks tend to be more robust to random shocks. Gai et al. (2011) also explore the differing consequences of a targeted shock which affects the most interconnected interbank lender under both network configurations. Contagion occurs more frequently

\footnotetext{
${ }^{30}$ See Amini et al. (2013) for a generalization of their results.

${ }^{31}$ Lee (2013) proposes a method for calculating systemic liquidity shortages in the network context.

${ }^{32}$ This tipping point behavior has been generalized by Georg (2013) to a dynamic setting.
} 
under both distributions, but for the less concentrated network, it makes only a small difference. For the concentrated network it makes contagion quasi-certain for a very wide range of average degrees. What drives this result is that the most connected bank under a Poisson distribution is not much more connected than the average bank, whereas under the fat-tailed distribution the most connected bank is connected to a large part of the network. This reflects another result by Albert et al. (2000) that fat-tailed networks are vulnerable to targeted attacks on key nodes.

Nier et al. (2007) also explore the consequences of a targeted shock in a tiered network structure. They take the tiered structure to the extreme, with one large bank and 24 small banks forming a star network. The single large bank is the central node in the star network. Nier et al. (2007) then vary the number of links between the large bank and the small banks. When the shock hits a small bank, contagion decreases monotonically as more small banks become connected to the large bank. When the shock hits the large bank, the relationship between interconnectedness and financial contagion is nonmonotonic. Defaults first increase in connectivity. When the large bank is linked to ten small banks or more, defaults start decreasing.

Finally, Gai et al. (2011) change the complexity of the network. They increase activity on the unsecured interbank market, increasing interbank liabilities from 15 to 25 percent on each bank's balance sheet. Contagion occurs more frequently than in the baseline, which is intuitive because the overall rise in interbank liabilities increases the likelihood of larger funding withdrawals which cannot be absorbed by liquid assets. Nier et al. (2007) also find that the size of interbank liabilities tends to increase the risk of cascading failures, even if banks hold capital against such exposures.

Glasserman and Young (2014) estimate the extent to which defaults and losses are magnified by the interbank network over and above the original shocks to asset values. They compute the probability that default at a given node causes defaults at other nodes via network spillovers. They then compare the resulting probability with the probability that all of these nodes default by direct shocks to their outside assets with no network transmission. They find that losses attributable to the network are modest under a wide range of shock distributions. In addition, they find that the network is particularly vulnerable to contagion when the originating node is large and highly leveraged.

\subsection{Indirect linkages}

This section will survey the literature on indirect linkages in financial networks. Indirect connections include cross-holdings of shares (Elliott et al., 2014), multiple assets (Caccioli et al., 2014) and linked portfolio returns (Lagunoff and Schreft, 2001). As with the theoretical literature dealing exclusively with the direct channel, these studies also focus on the network structure and the nodes' characteristics and how these influence contagion. Important characteristics of the network are diversification, integration and bank leverage.

In Lagunoff and Schreft (2001) agents hold portfolios that are linked in the sense that the return of an agent's portfolio depends on the portfolio allocations of other agents. All portfolio linkages taken together constitute the financial network. Shocks lead agents 
to reallocate their portfolios, thereby breaking some links. Two types of financial crises are considered. The first type arises when agents do not foresee the possibility of losses. Then the unraveling of the financial crisis is gradual, as agents successively sever links. The second type occurs instantaneously when agents can foresee the losses and shift their portfolios ex ante.

In Elliott et al. (2014), organisations are connected through cross-holdings of shares which constitute the network. Via these cross-holdings, the organizations' values depend on each other. If an organization's value falls below a certain threshold such that it fails, these losses will affect its counterparties and these will propagate the losses further via their counterparties. Relatively small and organisation-specific shocks can be amplified in this way. Elliott et al. (2014) show how the probability and the magnitude of cascades depends on two characteristics of the cross-holdings. The first aspect is integration, which refers to the level of exposure of organizations to each other. Increasing integration leads to an increase in exposures which tends to increase the probability and magnitude of contagion. The second characteristic is diversification which refers to how spread out cross-holdings are. Depending on the level of diversification, a failure of one organization can have very different effects. In the case of low diversification, some organization can be very dependent on the stability of others, but the low density of the network limits propagation. For an intermediary level of diversification, the network is dense enough for cascades to occur, but at the same time cross-holdings are still large, so that an individual failure leads to far-reaching cascades. When diversification is high, organizations become insensitive to another organization's failure. In summary, an economy is particularly vulnerable to cascades when both integration and diversification are at intermediate levels, since connections exist to propagate shocks and organizations hold enough shares of others for these drops in value to matter.

Caccioli et al. (2014) generalize the model of fire-sale dynamics by Cifuentes et al. (2005) to the case of many assets. They build a network of banks and assets, where banks have overlapping portfolios. Like Elliott et al. (2014), Caccioli et al. (2014) are interested in the effect of diversification on the stability of the network, adding the possibility for banks to be leveraged. The effect of diversification confirms the three phases found by Elliott et al. (2014) for high, intermediate and low diversification. Furthermore, Caccioli et al. (2014) find that higher leverage increases the overall instability of the network.

\subsection{Interactions between direct and indirect linkages}

The vast majority of empirical financial network simulation studies find little potential for failures resulting from direct interbank linkages. ${ }^{33}$ Banks have however many more types of links than just direct interbank exposures. Indirect links between banks exist when the portfolios of financial institutions overlap due to investment in common assets. The literature reviewed in this section combines direct and indirect links in an interbank network. Combining these features not only shows how shocks are propagated, but is also able to capture how shocks are amplified. The amplification mechanism in these

\footnotetext{
${ }^{33}$ See Upper (2011) and Summer (2013) for a survey on the results of this literature.
} 
models is mainly driven by fire sales. From a risk perspective, these models interact counterparty risk resulting from direct exposures with liquidity risk resulting from the fire sales channel.

Cifuentes et al. (2005) build a theoretical model of an interbank network and combine direct linkages with indirect linkages via overlapping asset portfolios of banks. Notably Cifuentes et al. (2005) show that when the prices of fire sold assets are allowed to change endogenously, the impact of an initial shock may be considerable. The propagation works as follows. The initial shock is the failure of one bank in the network. The remaining assets of the bank are sold on the market. When the market's demand for illiquid assets is less than perfectly elastic, sales by distressed institutions depress the market prices of such assets. The amplification of the shock results from a mark-to-market regime. The update of the asset prices can induce a further round of endogenously generated sales of assets, depressing prices further and inducing further sales. In this simple setup, Cifuentes et al. (2005) are able to show that small shocks can amplify contagion. ${ }^{34}$

Gai and Kapadia (2010) incorporate the setup by Cifuentes et al. (2005) into an interbank network with direct exposures. They find that adding an indirect channel does not alter the robust-yet-fragile property of the original network. Nier et al. (2007) also extend their model of direct exposures with the fire sales model by Cifuentes et al. (2005). Generally, liquidity risk increases contagious default for any level of connectivity. Furthermore, they find that more concentrated systems are fragile in particular when markets are illiquid. The intuition is that in a concentrated system, the default of one of the large banks requires the liquidation of a large part of the banking system. This can quickly drive down market valuations for the remaining banks, exacerbating asset price contagion for concentrated systems relative to less concentrated systems.

Like Cifuentes et al. (2005), Glasserman and Young (2014) also explore the effect of a mark-to-market regime on financial stability. The main difference in their setup is that assets do not need to be firesold to generate instability. In addition to the direct spillovers channel, Glasserman and Young (2014) incorporate confidence crises, where the bank's perceived ability to pay declines, causing the market value of its liabilities to fall. ${ }^{35}$ In a mark-to-market regime this reduction in value can spread to other institutions who also hold these liabilities among their assets. Such a confidence crisis can then leave these connected institutions highly vulnerable. Glasserman and Young (2014) show that this channel of contagion is likely to be considerably more important than direct spillover effects.

Caccioli et al. (2015) want to explain a paradox between recent empirical (Upper, 2011) and theoretical studies (Glasserman and Young, 2014), which both suggest that networks of direct exposures are not an important source of systemic risk, and the stylized fact that in the aftermath of Lehman Brother's bankruptcy liquidity dried up in

\footnotetext{
${ }^{34}$ In the macro-finance literature, endogenous asset price changes due to firesales are also an important modeling device to generate the amplification of initially small negative shocks. See section two of the survey by Brunnermeier et al. (2013).

${ }^{35}$ For the impact of confidence on contagion in interbank networks, see also May and Arinaminpathy (2009) and Arinaminpathy et al. (2012).
} 
interbank markets. ${ }^{36}$ Caccioli et al. (2015) wonder why market participants avoid being connected to one another if such connections do not represent a large risk. They argue that this apparent contradiction can be explained in terms of the interaction between counterparty risk and liquidity risk. Interbank lending stopped after the collapse of Lehman Brothers because market participants were aware that overlapping portfolios could deteriorate their positions and make them over-exposed to their counterparties. ${ }^{37}$ In order to show the importance of considering both counterparty and liquidity risk, Caccioli et al. (2015) simulate shocks in an interbank network using Austrian data on direct exposures. Then, they add a theoretical model of indirect interbank linkages based on Cifuentes et al. (2005), where they connect all banks in the network to a unique common asset. ${ }^{38}$ Caccioli et al. (2015) find that the system is rather stable after the failure of a single bank if counterparty risk is the only contagion mechanism. Then, they add the possibility of indirect contagion following a shock to the common asset. Combining counterparty risk with overlapping portfolio risk, contagion is strongly amplified, resulting in much larger cascading failures than would be observed otherwise.

Caballero and Simsek (2013) model a network of cross exposures between financial institutions that is susceptible to default cascades. Banks have only local knowledge of cross exposures: they understand their own exposures, but they are increasingly uncertain about cross exposures of banks that are farther away (in the network) from themselves. During normal times, banks only need to understand the financial health of their direct counterparties. In contrast, when a surprise liquidity shock hits parts of the network, a domino effect of bankruptcies becomes possible, and banks become concerned that they might be indirectly hit. Banks now need to understand the financial health of the counterparties of their counterparties (and their counterparties). Since banks only have local knowledge of the exposures, they cannot rule out an indirect hit. They now perceive significant counterparty risk that leads them to retrench into a liquidity conservation mode. This structure exhibits strong interactions with secondary markets for banks' assets. Banks in distress can sell their legacy assets to meet the surprise liquidity shock. If the shock is small, buyers rule out an indirect hit and absorb the fire sold assets. If the shock is large, banks start hoarding liquidity as a precautionary measure and buyers turn into sellers, exacerbating the fire sales.

Anand et al. (2013) push the analysis of interactions further by combining three sets of agents: domestic banks, overseas banks and firms. The model is then calibrated to advanced country banking sector data. The model highlights how shocks are propagated through the direct interlinkages of claims and obligations amongst (and between) domestic banks and overseas banks. But it also shows how defaults across the network are amplified by asset fire sales and lending is curtailed in the macroeconomy as credit

\footnotetext{
${ }^{36}$ For an empirical study of interbank market freezes from a network perspective, see Gabrieli and Georg (2014).

${ }^{37}$ This confirms results of more traditional macro finance models by Geanakoplos (2010) and Brunnermeier and Pedersen (2009) that market liquidity and funding liquidity are mutually reinforcing and their interaction can lead to liquidity spirals.

${ }^{38}$ While the focus of this survey is on theoretical models and not on simulation studies, the paper by Caccioli et al. (2015) has been included because it incorporates a theoretical model into the simulation.
} 
crunch effects take hold in the event of distress. In addition, they illustrate how greater heterogeneity of bank balance sheets leads to more realistic outcomes, characterized by the failure of some but not all banks in extreme scenarios.

\section{Network formation}

One limitation of static models of financial networks, is that they do not provide an account of link formation, that is, they do not model the dynamic process by which financial institutions enter into obligations to one another in the first place. This challenge has been taken up recently in the financial networks literature. ${ }^{39}$

Three main ways to model network formation have crystallized in the interbank networks literature. One branch of the literature borrows ideas from network growth models. Typically, these are random network models where new nodes are born over time and form attachments to existing nodes when they are born. ${ }^{40}$ In the financial networks literature, an empty network ${ }^{41}$ is given and link formation is then done in a mechanical way between the nodes in the network. One option is to generate links according to a stochastic process (Anand et al., 2012). Another option is to condition link formation on characteristics of the nodes, such as their profits (Lenzu and Tedeschi, 2012) or their willingness to extend an interbank loan (Lux, 2014). This process of network formation is called preferential attachment. Trust is an important element in this regard. Banks trust other banks based on their performance or their reliability in lending. An additional feature of preferential attachment is that it provides a mechanism to generate scale-free distributions (Barabási and Albert, 1999), which is also a feature of the interbank network.

A second area uses strategic network formation, where banks assess the costs and benefits from forming a link with another bank (Blume et al., 2013). A prominent theme in strategic network formation are rollover decisions by banks, often modeled using global games techniques. Creditors strategically decide to rollover a loan after receiving a signal about the solvency or performance of the borrower (Allen et al., 2012; Fique and Page, 2013; Anand et al., 2012). Closely related to strategic network formation are network formation games. A game of network formation specifies a set of players, the link formation actions available to each player and the payoffs to each player from the networks that arise out of individual linking decisions. Rollover decisions (Fique and Page, 2013) or decisions to enter preferential trading relationships in an interbank market (In't Veld et al., 2014) have been modeled as network formation games.

The third branch of this literature uses endogenous network formation. Banks choose the amount of interbank lending and/or borrowing by optimizing their (heterogeneous) balance sheets (Aldasoro et al., 2015; Bluhm et al., 2014b; Hałaj and Kok, 2015; Georg, 2013). The literature on endogenous network formation combines economic modeling techniques with the insight that interconnections need to be taken seriously.

\footnotetext{
${ }^{39}$ See Jackson (2005) for a survey of network formation models in economics.

${ }^{40}$ See chapter five in the textbook by Jackson (2010) for an overview of network growth models.

${ }^{41}$ In an empty network there are no links between the nodes.
} 


\subsection{Random link formation}

Models reviewed here combine elements from random link formation with strategic elements or with preferential attachment. Since the dominant driver for link formation is based on probabilities and stochastic processes, these models, although hybrid, have been categorized under random link formation.

\subsubsection{Combining random and strategic network formation}

Anand et al. (2012) want to understand how funding maturity and network structure interact to generate systemic financial crises. Their model combines strategic network formation with a dynamic model of network growth. The strategic aspect of the network formation lies in the rollover decision of the bank's creditors, modeled as a global game. Creditors receive adverse information about the bank's future profits and then decide to withdraw the funds or to roll over to maturity. The model shows how the arrival of bad news about a financial institution can lead others to lose confidence in it and how this, in turn, spreads across the entire system. Anand et al. (2012) are also able to compute endogenous default rates depending on the cost of miscoordination of the creditors and mean assets and liabilities. The dynamical evolution of the interbank system is based on a model of network growth. Links are created using a random matching framework. The formation of a debt contract between any two banks is a random draw from all possible contracts between banks in the network. The evolution of the interbank network is governed by three Poisson processes representing link addition, link decay and the arrival of adverse signals. They show that the system exhibits tipping-points and hysteresis. If the system tips into a bad state, the breakdown of the interbank market is persistent and a more favorable environment is required to re-start its normal functioning. The authors thereby provide a plausible account of the interbank credit freeze that characterized the global financial crisis of 2007/2008. Fique and Page (2013) generalize the results of Anand et al. (2012). They show that even without coordination failures, tipping points can occur depending on the importance of the network as an information propagation mechanism.

\subsubsection{Preferential lending and random link formation}

Preferential lending or relationship lending in the interbank market is empirically relevant. ${ }^{42}$ Models with exogenously given network structures have already shown the importance of confidence crises in driving contagion (May and Arinaminpathy, 2009; Arinaminpathy et al., 2012; Glasserman and Young, 2014). It turns out that trust is also a key driver in the formation of interbank relations.

Lenzu and Tedeschi (2012) model an interbank market with heterogeneous financial institutions that enter into lending agreements on different network structures. They implement an endogenous mechanism of link formation, via a preferential attachment

\footnotetext{
${ }^{42}$ See for example the empirical studies on relationship lending in the German (Bräuning and Fecht, 2012), Portuguese (Cocco et al., 2009) and Italian (Affinito, 2012) interbank markets.
} 
rule $^{43}$, such that each financial institution can enter into a lending agreement with others with a probability proportional to its profit. The key element in the model is the trust parameter. It captures how much banks trust the information about other agents' performances. By changing the agent's trust on its neighbor's performance, interbank linkages self-organize themselves into very different network architectures, ranging from random to scale-free topologies. Increasing the credibility of the information leads to a network structure that becomes more and more centralized around a small number of attractive borrowers. Lenzu and Tedeschi (2012) study which network architecture can make the financial system more resilient to random attacks and how systemic risk spreads over the network. To perturb the system, they generate a random attack via a liquidity shock. The hit bank is not automatically eliminated, but its failure is endogenously driven by its incapacity to raise liquidity in the interbank network. Their analysis shows that a random financial network can be more resilient than a scale-free one in case of agents' heterogeneity. The intuition behind this result is that the random graph compared with the scale-free one has a tendency to condense, forming regions of the graph that are essentially complete communities-subsets of nodes within which many possible lending paths exist.

In the dynamic model of the interbank market by Lux (2014), trust between banks is key in driving the emergence of a core-periphery structure. ${ }^{44}$ Starting from a given balance sheet structure of a banking system with a realistic distribution of bank sizes, the necessity of establishing interbank credit connections emerges from idiosyncratic liquidity shocks. Link formation is governed by a simple reinforcement-learning scheme. If there has been a previous successful attempt at obtaining credit from a certain bank, the borrower will have a higher tendency of contacting this creditor again. If credit is denied, the trust in this potential borrower will decline. As it turns out, the dynamic evolution of this system displays a formation of a core-periphery structure with the largest banks acting as intermediaries between many smaller banks.

Cohen-Cole et al. (2015) build a model that combines strategic decisions with network formation due to a variant of preferential attachment. They first build a static model of a bank, where bank profitability is based on competition incentives and the outcome of a strategic Cournot game. Lending decisions by the bank and its competitor's are captured in a network. Cohen-Cole et al. (2015) are then able to identify the equilibrium quantity of lending attributable to the network structure. This static model is then embedded into a dynamic model of network formation. The central modeling assumption of the dynamic network is that links are formed based on the profitability that emerges from the game in the static model.

\footnotetext{
${ }^{43}$ The network formation used here is based on Barabási and Albert (1999), who develop a method to generate power-law networks based on two features: (i) networks expand continuously by the addition of new nodes, and (ii) new nodes attach preferentially to nodes that are already well connected, called a preferential attachment rule.

${ }^{44}$ See also Fricke and Lux (2015a) and Langfield et al. (2014) for a discussion on why such coreperiphery structures may emerge in interbank markets.
} 


\subsection{Strategic network formation}

There are two central aspects to modeling networks from a strategic point of view. The first is that there must be explicit modeling of the costs and benefits that arise from various networks. This provides not only the possibility to model how networks form in the face of individual incentives to form or sever links, but also provides well-defined measures of overall societal welfare. Thus, it is possible to get predictions about which networks might form, but also get measures of which networks are best from society's point of view. The second aspect of modeling strategic network formation is making a prediction of how individual incentives translate into network outcomes. ${ }^{45}$

Blume et al. (2013) consider a very general case of strategic network formation, which can be readily applied to financial networks. The trade-off is the following: each agent receives benefits from the direct links it forms to others, but these links expose it to the risk of being hit by a cascading failure that might spread over multistep paths. In such a context, Blume et al. (2013) are able to provide asymptotically tight bounds on the welfare of optimal networks. Optimality of a graph is based on the Rawlsian notion of minimum welfare, defined as the minimum payoff of any node in the graph. They find that socially optimal networks are situated just beyond a phase transition in the behavior of the cascading failures. Their analysis also exposes a fundamental sense in which very small amounts of overlinking in networks with contagious risk can have strong consequences for the welfare of the participants.

Allen et al. (2012) develop a model in which asset commonality and short-term debt of banks interact to generate excessive systemic risk. Banks swap assets to diversify their individual risk. Each bank can exchange shares of its own investment project with other banks. Exchanging projects is costly as it entails a due diligence cost for each swapped project. In equilibrium, banks trade off the advantages of diversification in terms of lower default probability with the due diligence costs. The equilibrium concept used is one of a pairwise stable network. ${ }^{46}$ Two asset structures arise. In a ring network (the authors call it 'clustered structure'), groups of banks hold common asset portfolios and default together. When banks form two clusters of three banks each (the 'unclustered structure'), defaults are more dispersed. Portfolio quality of individual banks is opaque but can be inferred by creditors from aggregate signals about bank solvency. This signal is similar to a news shock familiar from the global games literature. When bank debt is short-term, creditors do not roll over in response to adverse signals and all banks are inefficiently liquidated. This information contagion is more likely under clustered asset structures. In contrast, when bank debt is long-term, welfare is the same under both asset structures.

\footnotetext{
${ }^{45}$ For further reading on strategic network formation, see chapter six in the textbook by Jackson (2010) or chapter seven in the textbook by Goyal (2012).

${ }^{46}$ According to Jackson and Wolinsky (1996), a network is pairwise stable i) if a link between two individuals is absent from the network then it cannot be that both individuals would benefit from forming the link, and ii) if a link between two individuals is present in a network then it cannot be that either individual would strictly benefit from deleting that link.
} 


\subsection{Network formation games}

Closely related to strategic network formation are network formation games. ${ }^{47}$ A game of network formation specifies a set of players, the link formation actions available to each player and the payoffs to each player from the networks that arise out of individual linking decisions.

Fique and Page (2013) model banks' rollover decisions within a network formation game. The equilibrium concept used here is a Nash equilibrium. Lenders are faced with the decision to rollover the debt that a borrower has outstanding, with the borrower's ability to repay being stochastic. In addition to a common prior distribution with respect to the borrower's solvency, each lender receives a private signal. Using this updated information and partially observing the network, each lender updates its beliefs and decides whether or not to rollover the outstanding debt. Since this lender's decision may be observed by another lender prior to its own rollover decision, favorable signals with respect to the borrower's creditworthiness are propagated slowly through the network. The speed of information diffusion depends on initial conditions and on the draws of nature. When uncertainty increases and signals are noisy, a creditor may become reluctant to refinance an investment opportunity even though the underlying economic fundamentals are solid.

In't Veld et al. (2014) build a network formation game with an explicit role for intermediation. They want to explore whether the core periphery structure can be explained by an intermediation role of core banks between periphery banks. Links in the network represent preferential trading relationships and a key assumption is that trade opportunities can only be realized if agents are linked directly or indirectly through intermediation by mutual trading relationships. Important drivers of the payoff structure in this context are the level of competition between intermediaries and the number of intermediaries. They identify which networks arise in equilibrium if banks optimally form links with other banks for interbank trading. With homogeneous banks, core periphery networks are unstable. Best-response dynamics converge to a unique stable outcome that ranges from an empty network (if linking costs are high) to a complete network (if linking costs are low). Then, In't Veld et al. (2014) introduce heterogeneity in their model by considering small banks and big banks, where big banks have more frequent trading opportunities. For sufficiently large differences between big and small banks, the core periphery network becomes a stable structure.

\subsection{Endogenous network formation}

In most of the literature on endogenous interbank network formation, banks are optimizing agents. Two approaches can be distinguished in the literature. The first is where banks choose the amount of interbank lending and/or borrowing by optimizing their (heterogeneous) balance sheets (Bluhm et al., 2014a,b; Aldasoro et al., 2015). This optimal amount then gets allocated among the banks. A second option is to fix the overall

\footnotetext{
${ }^{47}$ For an overview of network formation games, see chapter eleven of the textbook by Jackson (2010).
} 
amount of borrowing and lending (Georg, 2013; Hałaj and Kok, 2015). Banks then have the choice of their counterparty.

Bluhm et al. (2014b) include the fire sales model of Cifuentes et al. (2005) into a model with endogenous network formation. Bluhm et al. (2014b) construct a dynamic network model with risk neutral, heterogeneous and micro-founded banks, whose links emerge endogenously from the interaction of intermediaries' optimizing decisions and an iterative tâtonnement process which determines market prices endogenously. The financial system featured in their model consists of a network with a finite number of financial institutions which solve an optimal portfolio problem, taking into account liquidity and capital constraints. Banks hold different amounts of equity capital and differ for the returns on non-liquid assets. Such differences in returns give rise to heterogeneous optimal portfolio allocations of banks' assets and residual liabilities, hence to excess demand or supply of bank borrowing and lending. Links among banks are determined by lending and borrowing decisions that are cleared and settled in the interbank market. Contagion occurs through interbank linkages and fire sale externalities. Aldasoro et al. (2015) extend this model beyond the combination of the direct and the indirect contagion channel by including liquidity hoarding by risk averse banks. The resulting network configuration is able to match key characteristics of empirical interbank networks and exhibits a core-periphery structure, dis-assortative behavior and a low clustering coefficient.

Hałaj and Kok (2015) also model risk averse banks and include the possibility of rollover risk, while they abstract from the possible impact of fire sales of assets as in Bluhm et al. (2014b) and Aldasoro et al. (2015). Hałaj and Kok (2015) take a sample of 80 large EU banks and based on their balance sheet composition assume that they optimize their interbank assets taking into account risk and regulatory constraints as well as the demand for interbank funding. This optimization process results in a preferred interbank portfolio allocation for each bank in the system. For what concerns the funding side, banks define their most acceptable structure of funding sources with the objective of limiting rollover risk. Banks then meet in a bargaining game in which the supply and demand for interbank lending is determined by allowing banks to marginally deviate from their optimal interbank allocations and the prices they offer on those. In order to account for the quite complex aspects of the interbank market formation Hałaj and Kok (2015) propose a sequential optimization process, which is repeated in an iterative manner until a full allocation of interbank assets is achieved. The emerging network is then used as a tool for analyzing the impact of various regulatory policy measures relating to banks' incentives to operate in the interbank market.

Georg (2013) compares different network structures where the nodes are banks choosing an optimal portfolio. Banks face a stochastic supply of household deposits and stochastic returns from risky investments. This gives rise to liquidity fluctuations and initiates the dynamic formation of an interbank loan network. Georg (2013) analyzes the impact of the financial network structure on financial stability. He shows that in random graphs the relationship between the degree of interconnectivity and financial (in-)stability is non-monotonic, thereby generalizing the result of Nier et al. (2007) to a dynamic setting. In times of distress, core-periphery networks are seen to be more 
stable than purely random networks. In tranquil times, however, he shows that different interbank network structures do not have a substantial effect on financial stability. The key intuition behind this behavior is a regime switching property of the model financial system. In tranquil times, liquidity demand driven interbank lending is low and cascading defaults are thus contained. In times of crisis, individual banks suffer larger liquidity fluctuations and engage in higher liquidity-driven interbank lending. This drives the financial system as a whole into a contagious regime. When exactly the regime switching behaviour occurs depends on the interbank network structure.

Aymanns and Georg (2015) do not base endogenous network formation in their model on the optimal portfolio decisions of banks. Rather they borrow from the existing literature on Bayesian learning in social networks. They allow banks to endogenously form links based on the utility they get from an improved social belief about peer behavior in a first stage of the model. In the second stage of the model agents then learn about the state of the world and take their investment decisions.

\section{$5 \quad$ Policy insights from interbank networks}

Representing the banking system as a network is arguably more realistic than to model it as a representative bank, as traditional macro finance models do. For this reason, the network literature can be a useful source for policy insights on financial stability. Not just recently have financial stability experts at central banks, supervisory authorities and international financial organizations become interested in the policy applications of network analysis. For example, the Bank of England's chief economist Andrew Haldane has been an early promoter of the network approach to financial systems (Haldane, 2009; Haldane and May, 2011; Gai et al., 2011). The European Central Bank held already in 2009 a workshop on 'Recent advances in modeling systemic risk using network analysis'. ${ }^{48}$ The IMF has recently reviewed tools used to identify and measure interconnectedness in the context of prudential policy (Arregui et al., 2013). ${ }^{49}$ Here we will briefly touch on the literature on network measures for identifying critical institutions, discuss stress testing using network models and then turn to policy insights for monetary and macroprudential policy.

\subsection{Identifying critical institutions}

Identifying critical financial institutions is important for policy-makers. ${ }^{50}$ There is a growing awareness that not only the size of an institution matters, but also its interconnectedness. Network concepts can be very useful to assess both interconnectedness and key banks in the financial system (Arregui et al., 2013). Two measures stand out in this

\footnotetext{
${ }^{48}$ The detailed summary of the workshop can be found here http://www.ecb.europa.eu/pub/pdf/ other/modellingsystemicrisk012010en.pdf.

${ }^{49}$ See also the IMF study by Chan-Lau et al. (2009) for a comparison of the network approach with other methods to assess direct and indirect financial interconnectedness.

${ }^{50}$ See for example the methodology to identify systemically relevant banks by the Basel Committee on Banking Supervision (2013).
} 
regard. The first one is centrality (Borgatti, 2005). Centrality measures infer from the pattern of linkages among financial institutions the extent to which a node is 'central' in the financial network. The second measure is clustering, which separates the network into subgroups ('clusters') of nodes that have closer connections to each other than with those outside the cluster. It can help identify subgroups of nodes with close connections and 'gatekeeper' institutions or systems that bridge across different clusters allowing for the contagion to spread out. ${ }^{51}$

Langfield and Soramäki (2014) provide an in-depth overview of the network literature on identifying systemically important banks. Measures to identify critical institutions include 'DebtRank' (Battiston et al., 2012c), SinkRank (Soramäki and Cook, 2013) or measures based on input-output analysis for singlelayer (Aldasoro and Angeloni, 2015) and multilayer networks (Aldasoro and Alves, 2015). A general overview of systemic risk measures is provided by Bisias et al. (2012).

\section{2 $\quad$ Stress testing}

Central banks, supervisory authorities and policy institutions such as the IMF are currently developing tools for stress testing the banking sector using network models (Anand et al., 2014a; Canedo and Jaramillo, 2009; Chan-Lau et al., 2009; Espinosa-Vega and Solé, 2014; Hałaj and Kok, 2015). According to the definition of the Basel Committee on Banking Supervision, stress testing is a tool used by authorities to quantify the impacts that large but plausible negative shocks could have on the capital positions of banks.

Supervisory authorities can apply network analysis to identify systemic and vulnerable institutions, as well as for tracking potential contagion paths. Espinosa-Vega and Solé (2014) suggest that network analysis could be combined with regular stress testing exercises in order to gain a more comprehensive picture of fragility in a given banking system. This combination of regular stress testing and network analysis could be done in two ways. The first option is to run traditional stress tests to identify the types of shocks that could have the largest first-round effects on individual institutions. Once these shocks are determined, they could be fed into a network model to assess second(and higher) round effects. The second option is to begin with network analysis and to apply a first set of shocks to the financial system in order to identify those institutions that are more systemic and vulnerable and then proceed with a more thorough stress test of some selected institutions. Hałaj and Kok (2015) combine a stress testing exercise with their model of endogenous network formation. By optimizing the risk-adjusted profitability banks decide about the allocation of assets to the interbank portfolio. The optimization involves many economic parameters describing banks' financial standing and their economic environment. This allows for passing through stress testing scenarios to project the evolution of asset structures under adverse conditions and then applying the framework for endogenous interbank interbank formation to analyse changes in the

\footnotetext{
${ }^{51}$ See for example ECB (2006) for an application of cluster analysis to identify systemically relevant banks.
} 
topology of the interbank market.

Espinosa-Vega and Solé (2014) also highlight the challenges ahead. They emphasize that it is still very difficult to obtain comprehensive information at the bank level. Some of the areas where better data are needed include information on banks' exposures and funding positions, with breakdowns by counterparty, currency, and remaining maturity. Additional data on off-balance-sheet and shadow banking activities would also make stress testing more informative. Chan-Lau et al. (2009) also discuss the importance of filling existing information gaps on cross-market, cross-currency, and cross-country linkages to refine analyses of systemic linkages.

\subsection{Insights for monetary policy}

The question as to whether and how monetary policy can foster financial stability has always played a prominent role in the macro finance literature and it has become paramount after the recent global financial crisis. In macro models this question has typically been answered by analyzing whether targeting financial variables in operational monetary policy rules can smooth the volatility of asset prices and other financial variables. But this modeling framework neglects important aspects of financial instability, namely the diffusion of risk through firesale spirals and direct interconnections within the banking system. These network features are crucial characteristics of the interbank market, where monetary policy implementation takes place through the supply of liquidity and interest rate expectations. As Bluhm et al. (2014b) highlight, central bank interventions can affect market liquidity as well as systemic risk. On the one side, increased liquidity allows banks to be resilient to adverse shocks. On the other side, an implicit monetary policy guarantee can generate moral hazard and lead to higher risk taking. This carries an externality, increasing the likelihood of adverse shock transmission to the overall banking system as well as the real economy.

Central banks are introduced into the interbank network by allowing one bank either to supply an unlimited amount of liquidity (Bluhm et al., 2014b) or to provide liquidity against eligible collateral (Georg, 2013). Bluhm et al. (2014b) analyze the effect of monetary policy on financial stability using an interbank network with endogenous link formation. Systemic risk is measured with the overall probability of the system to default. A financial crisis arises in the form of multiple bank defaults driven by direct contagion via the interbank market, common shock exposures on asset markets and firesale spirals as modeled in Cifuentes et al. (2005). The central bank injects or withdraws liquidity on the interbank markets to achieve its desired interest rate target. A tension arises between the beneficial effects of stabilized interest rates and increased loan volume and the detrimental effects of higher risk taking incentives. They find that central bank supply of liquidity quite generally increases systemic risk.

Georg (2013) also constructs an interbank market via endogenous network formation. Banks are both directly and indirectly connected. He shows that the central bank can stabilize the financial system in the short run. Central bank liquidity provision helps banks to withstand liquidity shocks for a longer time. This, however, allows banks that would otherwise be insolvent to engage in liquidity demand-driven interbank borrowing. 
The result is that the financial system as a whole is more highly interconnected and more likely to enter the contagious regime. He also shows that the introduction of a common shock hitting all banks simultaneously can cause substantial financial fragility but has a less severe impact on the liquidity provision of the interbank market. This finding is of particular importance for policymakers implementing emergency measures in times of a crisis: while interbank contagion requires mainly liquidity provision, a common shock requires banks to be recapitalized.

Freixas et al. (2000) find that the central bank has a role to play as a crisis manager. When all banks are solvent, the central bank's role of preventing a speculative gridlock is simply to act as a coordinating device. By guaranteeing the credit lines of all banks, the central bank eliminates any incentive for early liquidation. This entails no cost for the central bank since its guarantees are never used in equilibrium. When instead one bank is insolvent because of poor returns on its investment, the central bank has a role in the orderly closure of this bank. When a bank is to be liquidated, the central bank has to organize the bypass of this defaulting bank in the payment network and provide liquidity to the banks that depend on this defaulting bank. Furthermore, since the interbank market may loosen market discipline, there is a role for supervision, with the regulatory agency having the right to close down a bank even if this bank is not confronted with any liquidity problem.

\subsection{Insights for macro-prudential policy}

The cornerstone of the current international regulatory agenda is the setting of higher requirements for banks' capital and liquid assets. The traditional rationale for such requirements is that they reduce idiosyncratic risks to the balance sheets of individual banks. According to Haldane and May (2011), an alternative and more far-reaching interpretation is that they are a means of strengthening the financial system as a whole by limiting the potential for network spillovers. The theoretical network literature has done policy experiments to simulate the impact of different regulatory measures on systemic risk. The main regulatory measures analyzed are liquidity requirements, limits to counterparty credit risk using large exposure limits and credit valuation adjustments as well as capital requirements.

\subsubsection{Liquidity requirements}

Liquidity requirements are the minimum ratio of banks' liquid assets to their short-term liabilities. Haldane and May (2011) argue that liquidity ratios can be seen as a means of short-circuiting the potential for systemic liquidity spillovers arising from fire sales on the asset side of the balance sheet (liquidity shocks) or liquidity hoarding on the liabilities side (liquidity-hoarding shocks). In particular, holdings of liquid assets reduce the potential for market liquidity risk to propagate around the system, while limits on short-term liabilities reduce the spread of funding liquidity risk around the system.

Gai et al. (2011) simulate the effect of an introduction of two types of liquidity requirements in an interbank network. The first liquidity requirement is a uniform increase 
in liquid asset holdings. The authors find that imposing such a uniform liquidity requirement improves the resilience of the financial system. The second liquidity requirement imposes an increase in liquid assets that is positively related to banks' interbank assets. This allows an assessment of the impact of targeting higher liquidity requirements on key players in the interbank network. To make both simulations comparable, the average increase in liquid assets is identical in both policy exercises. The augmented liquidity rule is more effective in reducing the probability and spread of contagion than an equivalent across-the-board increase in liquid asset requirements.

Aldasoro et al. (2015) assess the role of prudential regulations in reducing systemic risk in an endogenous banking network. They find that increasing the liquidity requirement unequivocally reduces systemic risk and the contribution of each bank to it. As banks must hold more liquidity for precautionary motives, their exposures in the interbank market declines, which limits somewhat the scope for network externalities. Furthermore, the reduction in non-liquid assets is quite substantial, which markedly reduces the scope for pecuniary externalities. The reduction in non-liquid assets is so strong that there is an associated cost to it in terms of efficiency of the system, highlighting the existing trade-off between stability and efficiency.

\subsubsection{Limiting counterparty risk}

An advantage of network models is that they capture interconnections and therefore counterparty risk. From such a network perspective, preventing contagion means limiting counterparty risk. Hałaj and Kok (2015) simulate the effect of two measures intended to limit counterparty risk in a realistic interbank network where banks optimize their balance sheets based on the balance sheet composition of 80 large EU banks. The first measure they analyze is large exposure limits and the second is credit valuation adjustments.

The current EU standard for large exposure limits amounts to 25 percent of total regulatory capital. Hałaj and Kok (2015) test the sensitivity of the network structures to a variation of the 25 percent threshold. They observe that network structures (e.g. in terms of number of links of individual nodes) are relatively stable around and especially above the 25 percent threshold. By contrast, a more stringent approach to large exposure limits (i.e. moving the threshold towards 0 percent) could trigger substantial changes to the structure of banks' network connections. Intuitively, as limits on large exposures become more binding banks will have to reduce on the size of individual exposures and as result spread their interbank business across a wider range of counterparties.

The second policy simulation analyzes credit valuation adjustment, which is the difference between the risk-free portfolio value and the true portfolio value that takes into account the possibility of a counterparty's default. In other words, credit valuation adjustment is the market value of counterparty credit risk. It impacts the interbank asset structure decision-making process via the capital constraint whereby banks engaged in lending to riskier counterparties will generally face a comparatively higher capital charge to reflect the default risk of their interbank borrowers. Varying the credit valuation adjustment parameter from no additional capital charges for counterparty risk to a 
regime with the market-based credit risk valuation of the interbank exposures, Hałaj and Kok (2015) find that the interbank networks structure does not change substantially except for some smaller (and weaker) banks that are forced to accept less diversified funding sources. The reason for that is the shift of banks' interbank placements to more sound institutions as far as the market perception is concerned.

\subsubsection{Capital requirements}

A capital requirement is the amount of capital a financial institution has to hold as required by its regulator. It is defined in terms of a capital ratio, which is the percentage of a bank's capital (also called equity) to its risk-weighted assets. The bank's capital ratio has to be maintained above a certain threshold, as specified by the regulator.

Nier et al. (2007) find that the better capitalized banks are, the more resilient is the banking system against contagious defaults. This effect is non-linear. For very low levels (0 to 1 percent) of net worth to total assets, the number of defaults decreases dramatically. Between 1 and 4 percent of net worth, the number of defaults is constant and between 4 and 5 percent, defaults decrease to zero. But even if banks are well capitalised, levels of interbank activity beyond a certain threshold imply elevated systemic risk.

Bluhm et al. (2014b) analyze the evolution of systemic risk, non-liquid assets and interbank loans under different values of capital requirements. Systemic risk features a bell-shaped dynamic. For low levels of the capital requirement the extent of interbank lending is large and mostly driven by the banks with high returns on non-liquid assets. Since this drives up the interbank interest rates, only few highly profitable banks borrow large amounts of interbank funds. In this setting the system is 'robust-yet-fragile': if one of the highly leveraged banks is hit by a medium shock, its (many) creditors who each are transmitted a fraction of the shock can eventually buffer the loss without defaulting. However, a large shock to one of the creditor banks results in the default of a large proportion of the financial system, confirming the result by Gai and Kapadia (2010) that it matters where the shock hits in the network. As Bluhm et al. (2014b) gradually increase the capital requirement, the scope for leveraging is reduced. Therefore the demand from highly profitable banks declines, resulting in a lower interbank interest rate. The lower interest rate in turn increases the number of banks which borrow since their return on non-liquid assets is higher than the return on the interbank market. As the number of borrowers is increased while the number of lenders is reduced, each bank features fewer counterparties on the interbank market. Therefore the robust-yet-fragile system turns more to a fragile system because the shock to one of the (now increased number of) debtor banks is buffered by a lower number of creditors. Therefore systemic risk initially increases with the capital requirement ratio. However, as it is increased beyond 7 percent, the amount of funds exchanged on the interbank market as well as the investment in non-liquid assets decline, ultimately resulting in monotonously decreasing systemic risk.

Cifuentes et al. (2005) investigate the consequences of mark-to-market accounting of firm's balance sheets in the presence of capital requirements. A shock that reduces 
the market value of a firm's assets will elicit the disposal of assets. If the market's ability to absorb these sales is less than perfect, such disposals will result in a shortrun change in market prices. When assets are marked to market at the new prices, the minimum capital requirement may dictate further disposals. In turn, such disposals will have a further impact on market prices. In this way, the combination of mark-tomarket accounting and capital constraints have the potential to induce an endogenous response that far outweighs the initial shock. Cifuentes et al. (2005) argue that liquidity requirements may be more effective than capital buffers in forestalling systemic effects. When the residual demand curve is extremely inelastic, even a large capital buffer may be insufficient to prevent contagion, since the price impact of sales into a falling market would be very high. Liquidity requirements can internalize some of the externalities that are generated by the price impact of selling into a falling market.

Aldasoro et al. (2015) study the effect of an increase in the equity requirements. Systemic risk decreases, in particular for an initial range of values of the equity requirement. The scope for network externalities is persistently reduced as the share of interbank assets over total assets steadily declines to reach very low values in the upper range of the equity requirement parameter. While there is also a slight reduction in the scope for fire sales externalities, the reduction in non-liquid assets is relatively minor. Furthermore, evaluation based on input-output measures reveals that the system becomes more homogenous and the potential damage from interbank market collapses is markedly reduced. This comes at the expense of having less banks trade in the interbank market, with an associated reduction in its density.

To conclude this section on policy insights from the financial networks literature, we will briefly dwell on proposals to set systemic regulatory requirements, as for example suggested by Haldane and May (2011). They argue that looking at financial risk through a network lens indicates a fundamentally different rationale for prudential regulation. In their view, prudential regulation has become increasingly risk-based. But the risk in question to which regulation was then calibrated has tended to be institution-specific rather than systemic risk. Approaching capital requirements from a system-wide angle would require to set firms' capital requirements to equalize the marginal cost to the system as a whole of their failure. Gai et al. (2011) also find that requiring key players to hold more liquid assets than other banks is more effective in reducing the probability and spread of contagion than an equivalent across-the-board increase in liquid asset requirements. In other words, regulatory requirements would be set higher for those banks bringing greatest risk to the system; for example, because of their size or connectivity (Haldane and May, 2011; Arinaminpathy et al., 2012).

\section{Conclusion}

The literature on theoretical interbank networks has grown tremendously in the past years. While this literature has provided us with a number of important insights, a number of important research questions remain. I will use the conclusion to point out a number of open questions that future research might address. 
1. More research is needed on the effect of the network structure on contagion. Theoretical interbank network modeling needs to use more realistic network structures on which to analyze contagion processes. Since empirical studies now provide an increasing number of stylized facts on the interbank network topology, research needs to move beyond deriving results on random networks or on overly simplified structures. Theoretical models should indeed be able to replicate topological properties of real-world interbank networks.

2. The focus has been on direct links in the interbank market as well as indirect links in the form of common assets. Yet there are many more types of indirect links in the interbank market. For example credit risk transfers in the form of derivatives are an important source of potential contagion and should therefore be studied more carefully.

3. Most interbank network models in the literature are static and exogenously given. One limitation of these static models is that they do not provide a dynamic account of link formation. Research is moving in this direction, but most of the dynamic models still use probabilistic link formation by relying on network growth models or on preferential attachment rules. A few recent models rely on endogenous network formation, in which banks purposefully choose the amount of interbank lending and borrowing and thereby create the structure of the interbank network. More work is needed on how to incorporate bank behavior into interbank networks. More precisely, we need to include micro-founded models of bank's dynamic reactions to financial shocks and to changes in regulatory parameters.

4. A bigger effort should be made to compare results and to exploit complementarities between the financial network literature and the established macro finance literature, since both share similar research topics, such as the study of the propagation and amplification of shocks in the financial system, fire sales spirals, market liquidity or the fragility of financial intermediaries.

5. More research is also needed to evaluate the impact of macro-prudential policy instruments on the financial sector as well as the analysis of the interactions between different macro-prudential policy instruments. Similarly, the evaluation of the interactions between monetary policy and macro-prudential policy is also an interesting topic for further research. 


\section{References}

Acemoglu, D., Ozdaglar, A., and Tahbaz-Salehi, A. (2015). Systemic risk and stability in financial networks. American Economic Review, 105(2):564-608.

Affinito, M. (2012). Do interbank customer relationships exist? and how did they function in the crisis? learning from italy. Journal of Banking 83 Finance, 36(12):3163-3184.

Albert, R., Jeong, H., and Barabási, A.-L. (2000). Error and attack tolerance of complex networks. Nature, 406(6794):378-382.

Aldasoro, I. and Alves, I. (2015). Multiplex interbank networks and systemic importance: An application to european data. Unpublished manuscript.

Aldasoro, I. and Angeloni, I. (2015). Input-output-based measures of systemic importance. Quantitative Finance. Forthcoming in the Special Issue "Interlinkages and Systemic Risk".

Aldasoro, I., Delli Gatti, D., and Faia, E. (2015). Bank networks: Contagion, systemic risk and prudential policy. CESifo Working Paper No. 5182. DOI: 10.1080/14697688.2014.968194.

Allen, F. and Babus, A. (2009). Networks in finance. In Kleindorfer, P. R. and Wind, Y., editors, The network challenge: strategy, profit, and risk in an interlinked world, pages 367-382. Prentice Hall Professional.

Allen, F., Babus, A., and Carletti, E. (2012). Asset commonality, debt maturity and systemic risk. Journal of Financial Economics, 104(3):519-534.

Allen, F., Carletti, E., Krahnen, J.-P., and Mark, T. (2011). Liquidity and crises. Oxford University Press.

Allen, F. and Gale, D. (2000). Financial contagion. Journal of Political Economy, 108(1):1-33.

Alves, I., Ferrari, S., Franchini, P., Heam, J., Jurca, P., Langfield, S., Laviola, S., Liedorp, F., Sánchez, A., Tavolaro, S., and Vuillemey, G. (2013). The structure and resilience of the european interbank market. ESRB Occasional Papers, 3.

Amini, H., Cont, R., and Minca, A. (2013). Resilience to contagion in financial networks. Mathematical Finance. DOI: 10.1111/mafi.12051.

Anand, K., Bédard-Pagé, G., and Traclet, V. (2014a). Stress testing the canadian banking system: A system-wide approach. Bank of Canada Financial Stability Review.

Anand, K., Craig, B., and von Peter, G. (2014b). Filling in the blanks: network structure and interbank contagion. Quantitative Finance. DOI: 10.1080/14697688.2014.968195.

Anand, K., Gai, P., Kapadia, S., Brennan, S., and Willison, M. (2013). A network model of financial system resilience. Journal of Economic Behavior $\&$ Organization, 85:219 - 235.

Anand, K., Gai, P., and Marsili, M. (2012). Rollover risk, network structure and systemic financial crises. Journal of Economic Dynamics and Control, 36(8):1088-1100.

Arinaminpathy, N., Kapadia, S., and May, R. M. (2012). Size and complexity in model financial systems. Proceedings of the National Academy of Sciences, 109(45):18338-18343.

Arregui, M. N., Norat, M. M., Pancorbo, A., Scarlata, J. G., Holttinen, E., Melo, F., Surti, J., Wilson, C., Wehrhahn, R., and Yanase, M. (2013). Addressing interconnectedness: Concepts and prudential tools. IMF Working Paper Series, 13(199). 
Aymanns, C. and Georg, C.-P. (2015). Contagious synchronization and endogenous network formation in financial networks. Journal of Banking \& Finance, 50:273 - 285.

Barabási, A.-L. and Albert, R. (1999). Emergence of scaling in random networks. Science, 286(5439):509512 .

Bargigli, L., di Iasio, G., Infante, L., Lillo, F., and Pierobon, F. (2014). The multiplex structure of interbank networks. Quantitative Finance. DOI: 10.1080/14697688.2014.968356.

Basel Committee on Banking Supervision (2013). Global systemically important banks: updated assessment methodology and the higher loss absorbency requirement. Framework text, Bank of International Settlements.

Battiston, S., Gatti, D. D., Gallegati, M., Greenwald, B., and Stiglitz, J. E. (2012a). Default cascades: When does risk diversification increase stability? Journal of Financial Stability, 8(3):138 - 149.

Battiston, S., Gatti, D. D., Gallegati, M., Greenwald, B., and Stiglitz, J. E. (2012b). Liaisons dangereuses: Increasing connectivity, risk sharing, and systemic risk. Journal of Economic Dynamics and Control, 36(8):1121 - 1141.

Battiston, S., Puliga, M., Kaushik, R., Tasca, P., and Caldarelli, G. (2012c). Debtrank: Too central to fail? financial networks, the fed and systemic risk. Scientific reports, 2(541).

Bech, M. L. and Atalay, E. (2010). The topology of the federal funds market. Physica A: Statistical Mechanics and its Applications, 389(22):5223-5246.

Bhattacharya, S. and Gale, D. (1987). Preference shocks, liquidity and central bank policy. In Barnett, W. and Singleton, K., editors, New Approaches to Monetary Economics, pages 69-88. Cambridge University Press.

Billio, M., Getmansky, M., Lo, A. W., and Pelizzon, L. (2012). Econometric measures of connectedness and systemic risk in the finance and insurance sectors. Journal of Financial Economics, 104(3):535 559 .

Bisias, D., Flood, M., Lo, A. W., and Valavanis, S. (2012). A survey of systemic risk analytics. Annual Review of Financial Economics, 4(1):255-296.

Bluhm, M., Faia, E., and Krahnen, J. P. (2014a). Endogenous banks' networks, cascades and systemic risk. SAFE Working Paper Series, 12.

Bluhm, M., Faia, E., and Krahnen, J. P. (2014b). Monetary policy implementation in an interbank network: Effects on systemic risk. SAFE Working Paper Series, 46.

Blume, L., Easley, D., Kleinberg, J., Kleinberg, R., and Tardos, É. (2011). Which networks are least susceptible to cascading failures? In Foundations of Computer Science (FOCS), 2011 IEEE 52nd Annual Symposium on, pages 393-402.

Blume, L., Easley, D., Kleinberg, J., Kleinberg, R., and Tardos, E. (2013). Network formation in the presence of contagious risk. ACM Transactions on Economics and Computation, 1(2):6.

Borgatti, S. P. (2005). Centrality and network flow. Social networks, 27(1):55-71.

Boss, M., Elsinger, H., Summer, M., and Thurner, S. (2004). Network topology of the interbank market. Quantitative Finance, 4(6):677-684.

Bräuning, F. and Fecht, F. (2012). Relationship lending in the interbank market and the price of liquidity. Deutsche Bundesbank Discussion Paper, 2012(22). 
Brunnermeier, M. K., Eisenbach, T., and Sannikov, Y. (2013). Macroeconomics with Financial Frictions: A Survey. Cambridge University Press, New York.

Brunnermeier, M. K. and Pedersen, L. H. (2009). Market liquidity and funding liquidity. Review of Financial studies, 22(6):2201-2238.

Brusco, S. and Castiglionesi, F. (2007). Liquidity coinsurance, moral hazard, and financial contagion. The Journal of Finance, 62(5):2275-2302.

Caballero, R. J. and Simsek, A. (2013). Fire sales in a model of complexity. The Journal of Finance, 68(6):2549-2587.

Caccioli, F., Farmer, J. D., Foti, N., and Rockmore, D. (2015). Overlapping portfolios, contagion, and financial stability. Journal of Economic Dynamics and Control, 51:5063.

Caccioli, F., Shrestha, M., Moore, C., and Farmer, J. D. (2014). Stability analysis of financial contagion due to overlapping portfolios. Journal of Banking \& Finance, 46:233 - 245.

Canedo, J. M. D. and Jaramillo, S. M. (2009). A network model of systemic risk: stress testing the banking system1. Intelligent Systems in Accounting, Finance $\mathscr{G}$ Management, 16(1-2):87-110.

Chan-Lau, J., Espinosa, M., Giesecke, K., and Solé, J. (2009). Assessing the systemic implications of financial linkages. IMF Global Financial Stability Report, Chapter 2:73-110.

Cifuentes, R., Ferrucci, G., and Shin, H. S. (2005). Liquidity risk and contagion. Journal of the European Economic Association, 3(2-3):556-566.

Cocco, J. F., Gomes, F. J., and Martins, N. C. (2009). Lending relationships in the interbank market. Journal of Financial Intermediation, 18(1):24-48.

Cohen-Cole, E., Patacchini, E., and Zenou, Y. (2015). Static and dynamic networks in interbank markets. Network Science. DOI: 10.1017/nws.2015.1.

Craig, B. and von Peter, G. (2014). Interbank tiering and money center banks. Journal of Financial Intermediation, 23(3):322 - 347 .

Dasgupta, A. (2004). Financial contagion through capital connections: A model of the origin and spread of bank panics. Journal of the European Economic Association, 2(6):1049-1084.

De Bandt, O., Hartmann, P., and Peydro, J. (2012). Systemic risk in banking: An update. In Berger, A., Molyneux, P., and Wilson, J., editors, The Oxford Handbook of Banking, pages 633-672. Oxford University Press.

De Masi, G., Iori, G., and Caldarelli, G. (2006). Fitness model for the italian interbank money market. Phys. Rev. E, 74:066112.

Diamond, D. W. and Dybvig, P. H. (1983). Bank runs, deposit insurance, and liquidity. The Journal of Political Economy, pages 401-419.

ECB (2006). Identifying large and complex banking groups for financial system stability analysis. $E C B$ Financial Stability Review, pages 131-139.

Elliott, M., Golub, B., and Jackson, M. O. (2014). Financial networks and contagion. American Economic Review, 104(10):31153153.

Elsinger, H., Lehar, A., and Summer, M. (2006). Risk assessment for banking systems. Management Science, 52(9):1301-1314. 
Elsinger, H., Lehar, A., and Summer, M. (2013). Network models and systemic risk assessment. In Fouque, J.-P. and Langsam, J. A., editors, Handbook on Systemic Risk, pages 287-305. Cambridge University Press.

Espinosa-Vega, M. and Solé, J. (2014). Introduction to the network analysis approach to stress testing. In Ong, L., editor, A Guide to IMF Stress Testing: Methods and Models, chapter 13, pages 205-208. International Monetary Fund.

Fique, J. and Page, F. (2013). Rollover risk and endogenous network dynamics. Computational Management Science, 10(2-3):213-230.

Freixas, X. and Holthausen, C. (2005). Interbank market integration under asymmetric information. Review of Financial Studies, 18(2):459-490.

Freixas, X., Parigi, B. M., and Rochet, J.-C. (2000). Systemic risk, interbank relations, and liquidity provision by the central bank. Journal of Money, Credit and Banking, pages 611-638.

Fricke, D. and Lux, T. (2015a). Core-periphery structure in the overnight money market: Evidence from the e-mid trading platform. Computational Economics, 45:359-395.

Fricke, D. and Lux, T. (2015b). On the distribution of links in the interbank network: Evidence from the e-mid overnight money market. Empirical Economics. DOI: 10.1007/s00181-015-0919-x.

Furfine, C. H. (1999). The microstructure of the federal funds market. Financial Markets, Institutions E Instruments, 8(5):24-44.

Gabrieli, S. and Georg, C.-P. (2014). A network view on interbank market freezes. Bundesbank Discussion Paper, 44.

Gai, P., Haldane, A., and Kapadia, S. (2011). Complexity, concentration and contagion. Journal of Monetary Economics, 58(5):453-470.

Gai, P. and Kapadia, S. (2010). Contagion in financial networks. Proceedings of the Royal Society A: Mathematical, Physical and Engineering Science, 466(2120):2401-2423.

Garratt, R. J., Mahadeva, L., and Svirydzenka, K. (2014). The great entanglement: The contagious capacity of the international banking network just before the 2008 crisis. Journal of Banking 8 Finance, 49:367-385.

Geanakoplos, J. (2010). The leverage cycle. In NBER Macroeconomics Annual 2009, Volume 24, pages 1-65. University of Chicago Press.

Georg, C.-P. (2013). The effect of the interbank network structure on contagion and common shocks. Journal of Banking \& Finance, 37(7):2216-2228.

Georgescu, O.-M. (2015). Contagion in the interbank market: Funding versus regulatory constraints. Journal of Financial Stability, 18:1 - 18.

Glasserman, P. and Young, H. P. (2014). How likely is contagion in financial networks? Journal of Banking \& Finance. DOI: 10.1016/j.jbankfin.2014.02.006.

Goyal, S. (2012). Connections: an introduction to the economics of networks. Princeton University Press.

Hałaj, G. and Kok, C. (2015). Modeling emergence of the interbank networks. Quantitative Finance. DOI: $10.1080 / 14697688.2014 .968357$. 
Haldane, A. G. (2009). Rethinking the financial network. Speech delivered at the Financial Student Association, Amsterdam, April 2009.

Haldane, A. G. and May, R. M. (2011). Systemic risk in banking ecosystems. Nature, 469(7330):351-355.

Ho, T. S. and Saunders, A. (1985). A micro model of the federal funds market. The Journal of Finance, 40(3):977-988.

In’t Veld, D., van der Leij, M., and Hommes, C. (2014). The formation of a core periphery structure in heterogeneous financial networks. Tinbergen Institute Discussion Paper.

Iori, G., Masi, G. D., Precup, O. V., Gabbi, G., and Caldarelli, G. (2008). A network analysis of the italian overnight money market. Journal of Economic Dynamics and Control, 32(1):259 - 278.

Jackson, M. O. (2005). A survey of network formation models: Stability and efficiency. In Demange, G. and Wooders, M., editors, Group Formation in Economics, pages 11-57. Cambridge University Press. Cambridge Books Online.

Jackson, M. O. (2010). Social and economic networks. Princeton University Press.

Jackson, M. O. and Wolinsky, A. (1996). A strategic model of social and economic networks. Journal of economic theory, 71(1):44-74.

Laeven, L. and Valencia, F. (2013). Systemic banking crises database. IMF Econ Rev, 61(2):225-270.

Lagunoff, R. and Schreft, S. L. (2001). A model of financial fragility. Journal of Economic Theory, 99(1):220-264.

Langfield, S., Liu, Z., and Ota, T. (2014). Mapping the uk interbank system. Journal of Banking $\mathcal{G}$ Finance, 45:288 - 303 .

Langfield, S. and Soramäki, K. (2014). Interbank exposure networks. Computational Economics. DOI: $10.1007 / \mathrm{s} 10614-014-9443-\mathrm{x}$.

Lee, C. (2010). Graph theory and networks. In Blaug, M. and Lloyd, P. J., editors, Famous figures and diagrams in economics, pages 212-220. Edward Elgar Publishing.

Lee, S. H. (2013). Systemic liquidity shortages and interbank network structures. Journal of Financial Stability, 9(1):1 - 12 .

Leitner, Y. (2005). Financial networks: Contagion, commitment, and private sector bailouts. The Journal of Finance, 60(6):2925-2953.

Lenzu, S. and Tedeschi, G. (2012). Systemic risk on different interbank network topologies. Physica A: Statistical Mechanics and its Applications, 391(18):4331 - 4341.

Léon, C. and Berndsen, R. J. (2014). Rethinking financial stability: Challenges arising from financial networks' modular scale-free architecture. Journal of Financial Stability, 15(0):241 - 256.

Lux, T. (2014). Emergence of a core-periphery structure in a simple dynamic model of the interbank market. Journal of Economic Dynamics and Control. DOI: 10.1016/j.jedc.2014.09.038.

May, R. M. and Arinaminpathy, N. (2009). Systemic risk: the dynamics of model banking systems. Journal of The Royal Society Interface, 7(46):823-838.

Minoiu, C. and Reyes, J. A. (2013). A network analysis of global banking: 1978-2010. Journal of Financial Stability, 9(2):168-184. 
Mistrulli, P. E. (2011). Assessing financial contagion in the interbank market: Maximum entropy versus observed interbank lending patterns. Journal of Banking \& Finance, 35(5):1114 - 1127.

Montagna, M. and Kok, C. (2013). Multi-layered interbank model for assessing systemic risk. Kiel Working Paper, 1873.

Nier, E., Yang, J., Yorulmazer, T., and Alentorn, A. (2007). Network models and financial stability. Journal of Economic Dynamics and Control, 31(6):2033-2060.

Shin, H. S. (2010). Risk and liquidity. Oxford University Press.

Soramäki, K., Bech, M. L., Arnold, J., Glass, R. J., and Beyeler, W. E. (2007). The topology of interbank payment flows. Physica A: Statistical Mechanics and its Applications, 379(1):317 - 333.

Soramäki, K. and Cook, S. (2013). Sinkrank: An algorithm for identifying systemically important banks in payment systems. Economics: The Open-Access, Open-Assessment E-Journal, 7(2013-28):1-27.

Summer, M. (2013). Financial contagion and network analysis. Annual Review of Financial Economics, $5(1): 277-297$.

Tonzer, L. (2015). Cross-border interbank networks, banking risk and contagion. Journal of Financial Stability. DOI: $10.1016 / \mathrm{j} . j f s .2015 .02 .002$.

Upper, C. (2011). Simulation methods to assess the danger of contagion in interbank markets. Journal of Financial Stability, 7(3):111 - 125 .

Vivier-Lirimont, S. (2006). Contagion in interbank debt networks. Unpublished Manuscript.

Watts, D. J. and Strogatz, S. H. (1998). Collective dynamics of small-world networks. Nature, 393(6684):440-442. 
Appendix 


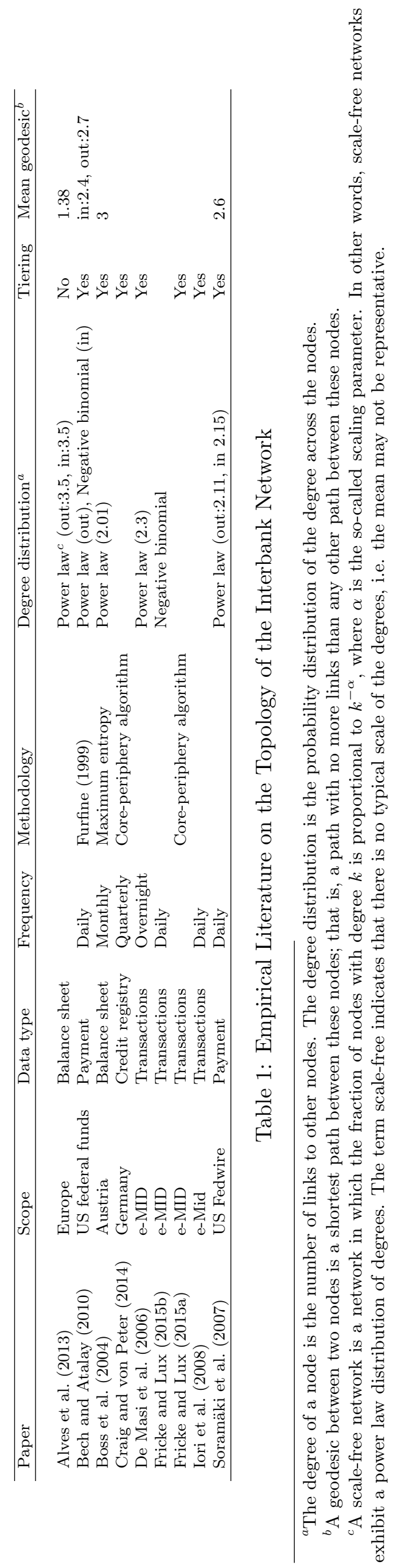




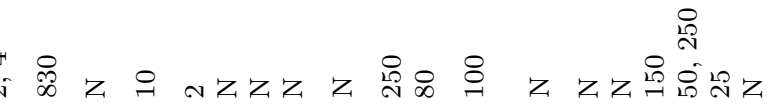

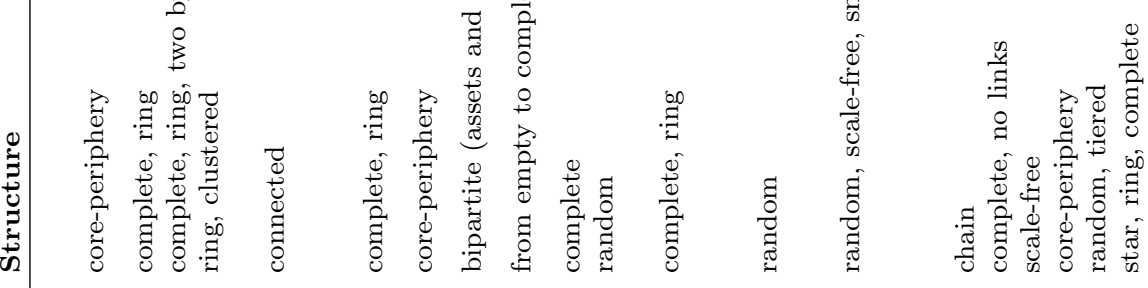

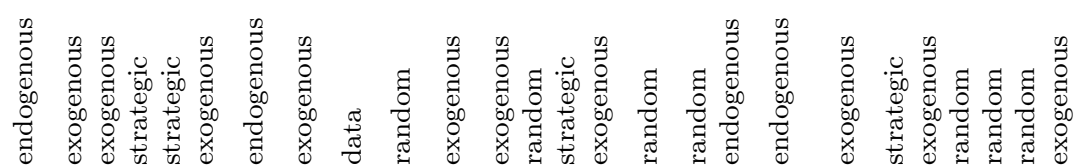
䔽

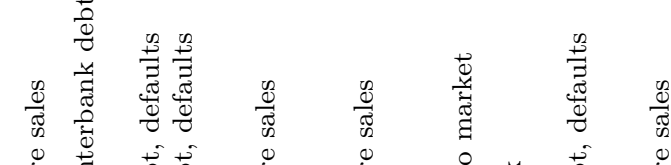

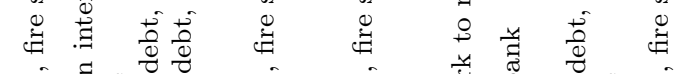

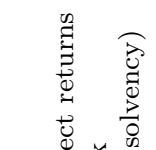

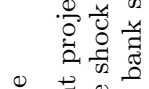

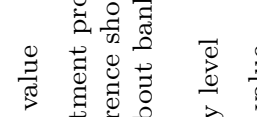

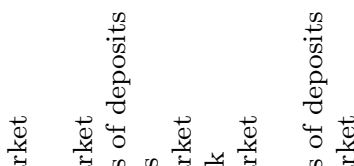

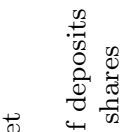

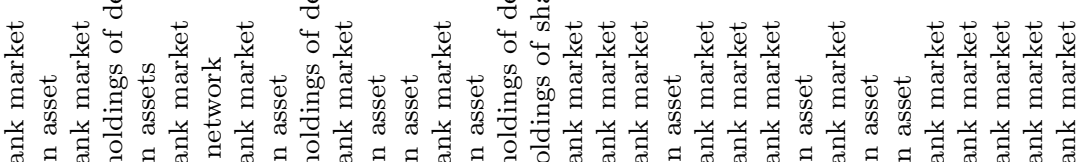

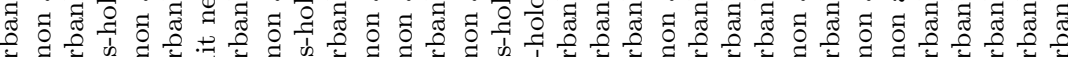

苗

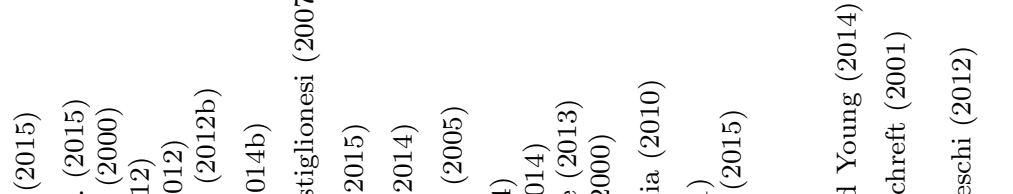

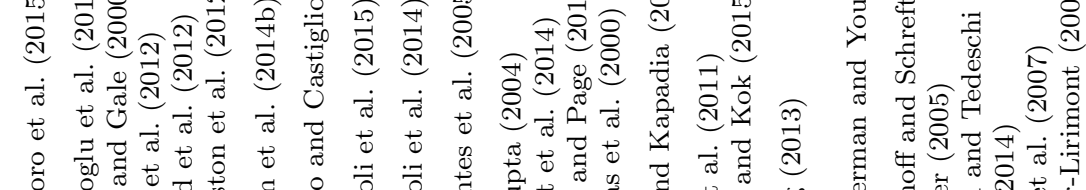

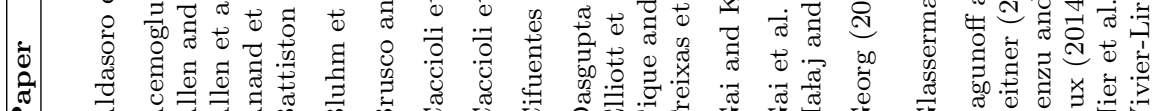

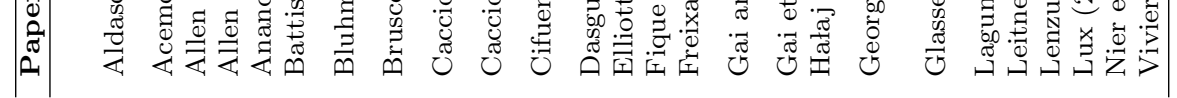




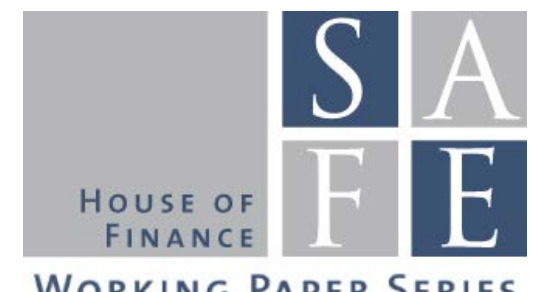

WORKING PAPER SERIES

\section{Recent Issues}

No. $90 \quad$ Pinar Topal

No. 89 Julia Braun, Alfons J. Weichenrieder

No. 88 Ester Faia, Beatrice Weder di Mauro

No. 87 Iñaki Aldasoro, Domenico Delli Gatti, Ester Faia

No. 86 Agar Brugiavini, Danilo Cavapozzi, Mario Padula, Yuri Pettinicchi

No. 85 Holger Kraft, Claus Munk, Sebastian Wagner

No.84 Raimond Maurer, Olivia S. Mitchell, Ralph Rogalla, Tatjana Schimetschek

No. 83 Patrick Grüning

No. 82 Edgar Vogel, Alexander Ludwig, Axel Börsch-Supan

No.81 Jens-Hinrich Binder

No. 80 Enrique G. Mendoza, Linda L. Tesar, Jing Zhang

No. 79 Òscar Jordà, Alan M. Taylor

No. 78 Harris Dellas, Dirk Niepelt

No. 77 Benjamin Born, Gernot J. Müller, Johannes Pfeifer

No. 76 Alberto Alesina, Carlo Favero, Francesco Giavazzi
Fiscal Stimulus and Labor Market Flexibility

Does Exchange of Information between Tax Authorities Influence Multinationals' Use of Tax Havens?

Cross-Border Resolution of Global Banks

Bank Networks: Contagion, Systemic Risk and Prudential Policy

Financial education, literacy and investment attitudes

Housing Habits and Their Implications for LifeCycle Consumption and Investment

Will They Take the Money and Work? An Empirical Analysis of People's Willingness to Delay Claiming Social Security Benefits for a Lump Sum

International Endogenous Growth, Macro Anomalies, and Asset Prices

Aging and Pension Reform: Extending the Retirement Age and Human Capital Formation

Resolution Planning and Structural Bank Reform within the Banking Union

Saving Europe?: The Unpleasant Arithmetic of Fiscal Austerity in Integrated Economies

The Time for Austerity: Estimating the Average Treatment Effect of Fiscal Policy

Austerity

Does Austerity Pay Off?

The Output Effect of Fiscal Consolidation Plans 